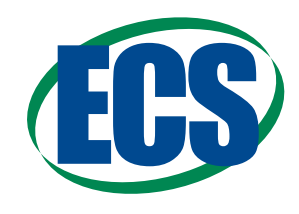

\title{
A Coupled Electrochemical-Thermal Failure Model for Predicting the Thermal Runaway Behavior of Lithium-Ion Batteries
}

\author{
Xuning Feng, $\oplus^{1,2}$ Xiangming He, ${ }^{1, z}$ Minggao Ouyang, ${ }^{2, z}$ Li Wang, ${ }^{1}$ Languang Lu, ${ }^{2}$ \\ Dongsheng Ren, $\mathbb{1}^{2}$ and Shriram Santhanagopalan ${ }^{3, *}$ \\ ${ }^{1}$ Institute of Nuclear and New Energy Technology, Tsinghua University, Beijing100084, People's Republic of China \\ ${ }^{2}$ State Key Laboratory of Automotive Safety and Energy, Tsinghua University, Beijing 100084, People's Republic of \\ China \\ ${ }^{3}$ Transportation and Hydrogen Systems Center, National Renewable Energy Laboratory, Golden, Colorado 80401, USA
}

\begin{abstract}
Thermal runaway is always a troublesome problem that hinders the safe application of high energy lithium-ion batteries. There is an urgent need to interpret the voltage and temperature changes and their underlying mechanisms during thermal runaway, in order to guide the safe design of a battery system. This paper is dedicated to building a coupled electrochemical-thermal model that can well predict the voltage drop and temperature increase during thermal runaway. The model can capture the underlying mechanism of (1) the capacity degradation under high temperature; (2) the internal short circuit caused by the thermal failure of the separator; and (3) the chemical reactions of the cell components that release heat under extreme temperature. The model is validated using by experimental data, therefore the modeling analysis has high fidelity. We employ the model to analyze 1) the capacity degradation under extreme temperature; 2) the influence of the SEI decomposition and regeneration on the thermal runaway behavior; 3) the heat generation by internal short circuit in the thermal runaway process. The discussions presented here help extend the usage of lithium-ion batteries at extreme high temperature $\left(>80^{\circ} \mathrm{C}\right)$, and guide the safe design of lithium-ion batteries with less hazard level during thermal runaway.

(C) The Author(s) 2018. Published by ECS. This is an open access article distributed under the terms of the Creative Commons Attribution 4.0 License (CC BY, http://creativecommons.org/licenses/by/4.0/), which permits unrestricted reuse of the work in any medium, provided the original work is properly cited. [DOI: 10.1149/2.0311816jes]

(cc) BY
\end{abstract}

Manuscript submitted September 4, 2018; revised manuscript received October 30, 2018. Published December 6, 2018.

Lithium-ion batteries are favored to be used in today's electrochemical energy storage systems, given their extended cycle life and high energy density. ${ }^{1}$ Higher energy density of lithium-ion batteries is required for applications with limited space, such as electric vehicles, ${ }^{2}$ space craft, ${ }^{3}$ smartphones, ${ }^{4}$ etc. However, higher energy density sacrifices the safety performance, ${ }^{5}$ which is raising more concerns in recent years. ${ }^{6-8}$ The safety problems always occurs with fire, ${ }^{9,10}$ explosion ${ }^{11}$ and toxicity, ${ }^{12}$ threatening the human lives and properties. A battery management system (BMS) should reduce the hazards of battery failure by monitoring the battery status. ${ }^{13-15}$ The common signals that a BMS relies on for fault diagnosis are voltage and temperature. ${ }^{16} \mathrm{~A}$ model that can simultaneously predict the voltage drop and temperature rise during battery failure will benefit the design of safer battery systems. ${ }^{17}$ Such a model should be capable of capturing the underlying coupled electrochemical-thermal mechanisms of battery failure at extreme temperature.

The coupled electrochemical-thermal failure of a lithium-ion batteries at extreme temperature includes some key processes: (1) the capacity degradation under high temperature, ${ }^{18}$ (2) the internal short circuit (ISC) caused by the failure of separator; ${ }^{19,20}$ (3) the chemical reactions of the cell components that release heat under extreme temperature, ${ }^{21,22}$ finally triggering thermal runaway(TR). ${ }^{23-26}$ (1) and (2) are more of electrochemical processes, and (3) is more of a chemical process. As all of the failure processes are triggered by temperature rise, the electrochemical-thermal model is highly coupled by temperature-related functions, e.g., heat generation by ISC, degradation caused by high temperature etc.

There are many available degradation models for predicting the degradation of lithium ion batteries. Empirical models have capacity as its only output, ${ }^{27}$ which is usually predicted by empirical equations. ${ }^{28}$ However, an empirical model does not consider correlated degradation mechanisms, e.g. loss of active materials (LAM), loss of lithium inventory (LLI), and ohmic resistance increase (ORI) etc., therefore it is hard for further establishing connections to degradation induced by high temperature. Upon this, a mechanistic model can help, because it can capture the degradation mechanism (LAM and LLI) based on the first principles. ${ }^{29,30}$ Christensen and Newman ${ }^{31,32}$ first proposed a mechanistic model whose parameters directly link with the LAM, LLI

*Electrochemical Society Member.

${ }^{\text {z} E-m a i l: ~ h e x m @ t s i n g h u a . e d u . c n ; ~ o u y m g @ t s i n g h u a . e d u . c n ~}$ and ORI of a lithium ion battery. The dynamics of LAM, LLI and ORI are described by Arrhenius type Equations. The growth of the solid electrolyte interface (SEI) film, which causes LLI and ORI, has been modeled in the literature $\mathrm{s}^{33-35}$ and relationship compatible with the mechanistic model have been identified. ${ }^{36}$ As the SEI decomposition and regeneration ${ }^{37,38}$ are important chemical processes pertinent to battery failure at high temperature, the modeling approaches need to be modified to describe the interactions between the electrochemicalthermal processes.

ISC, from which the electric energy of the cell can be released ${ }^{39,40}$ and the thermal runaway can be initiated, ${ }^{41,42}$, plays an important role in the battery failure process. ISC usually occurs when the separator fails to obstruct the contact of the cathode and anode due to various kinds of reasons, including mechanical crush, ${ }^{43,44}$ dendrite growth, ${ }^{45-47}$ separator shrinkage, ${ }^{48}$ etc. The heat generation during ISC is critical for a coupled electrochemical-thermal model. Zavalis ${ }^{49}$ et al. have built a detailed 2D electrochemical model that can simulate varies kinds of ISC. The distribution of ISC current and heat generation can be presented in 2D. Santhanagopalan ${ }^{50}$ et al. have modeled four kinds of ISC, pointing out that the joule heat is critical to initiate a temperature rise. Further studies started to use an equivalent resistance to control the degree of ISC in simulation, ${ }^{51-53}$ and can fit the experimental data well. ${ }^{54}$ Recently, Coman ${ }^{17}$ et al. pioneered the use of an efficiency factor to describe the proportion of electric energy that is converted into heat, considering the venting process, making it possible for further establishment of an electrochemical-thermal coupled battery failure model.

TR, which releases energy instantaneously, is a key prediction target of an electrochemical-thermal coupled model. Dahn's group ${ }^{55,56}$ pioneered in establishing a battery TR model using chemical kinetics that are described by Arrhenius type Equations. The kinetic parameters can be acquired from calorimetric tests. ${ }^{57,58}$ Spotnitz and Franklin ${ }^{21}$ summarized the reaction kinetics for several kinds of cell materials, and demonstrated the validity of the Dahn's TR model. The Dahn's TR model has further been modified for 3D TR simulation, ${ }^{59}$ and TR propagation within a battery pack ${ }^{42,60,61}$ in the following years. Coman et al. ${ }^{62,63}$ amended the venting process on the Dahn's TR model. Another recent trend is to combine the TR model with an electrochemical model together to simultaneously predict the voltage and temperature during TR. Lee ${ }^{64}$ et al. tried to combine the classical Dual-Foil electrochemical model ${ }^{65}$ with the TR model, and discussed 


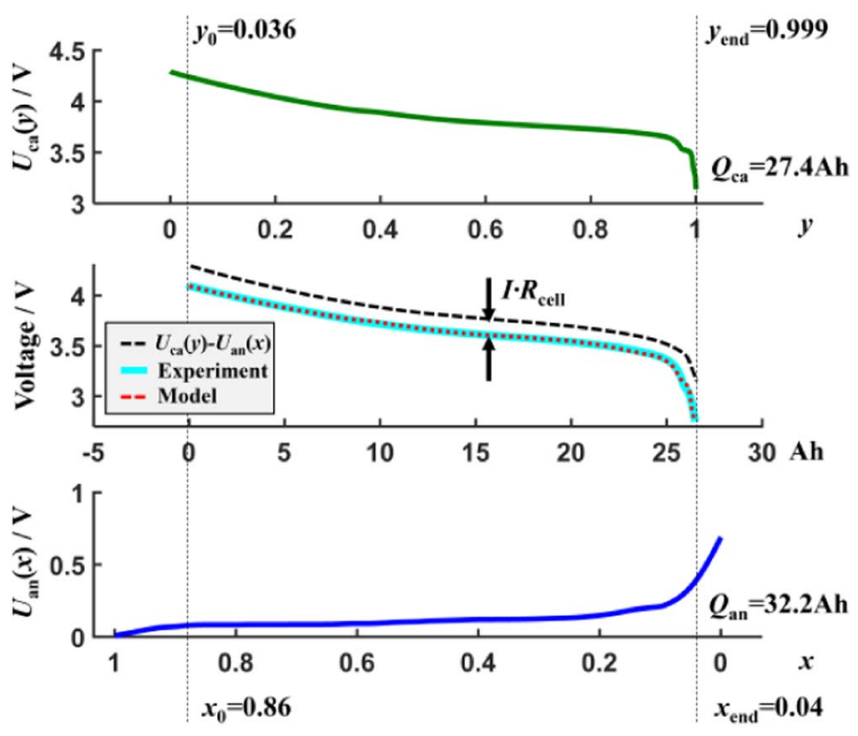

Figure 1. The electrochemical model to predict the voltage change during thermal runaway.

the influence of the design variables on the features of battery thermal runaway. Ping ${ }^{66}$ et al. built a $2 \mathrm{D}$ electro-thermal coupled model to predict the TR, which is triggered by the heat generated during cycling under adiabatic conditions. Both those models can simultaneously predict the battery voltage and temperature, however, they did not consider the influence of the high temperature on the electrochemical behavior, and could not simulate the degradation caused by exposing the cell components to high temperature. In other words, they implement one-way coupling by electrochemical $\rightarrow$ thermal, rather than thermal $\rightarrow$ electrochemical. Therefore the Step (1) in the thermal failure still cannot be well modeled to the best knowledge of the authors.

This paper aims to establish a coupled electrochemical-thermal model that can predict the voltage and temperature of the lithiumion battery during thermal runaway tests. Coupled electrochemicalthermal dynamics that can describe (1) the capacity degradation under high temperature; (2) the internal short circuit (ISC) caused by the thermal failure of separator; and (3) the chemical reactions of the cell components that release heat under extreme temperature, are built by specific mathematical functions with physical meanings. The voltage drop and temperature rise predicted by the coupled electrochemicalthermal model can fit well with the experimental data, whereas the predicted degradation also matches the test results. The analysis section discusses the capacity degradation under extreme high temperature exposure, the influence of the SEI regeneration on the total heat generation, and the critical conditions when an ISC triggers TR.

\section{Theoretical}

The electrochemical model.-The mechanistic model defined in Ref. 36 is used to simulate the electrochemical behavior of the lithiumion battery. The model assumes that the open-circuit-voltage of a full cell is the difference of the cathode potential $U_{\mathrm{ca}}(y)$ and the anode potential $U_{\text {an }}(x)$, as shown in Figure 1. The output voltage of the model should be calculated with additional voltage drop caused by ohmic potential loss, and that caused by entropy change at high temperature, as calculated in Eq. 1:

$$
V_{\mathrm{mdl}}=U_{\mathrm{ca}}(y)-U_{\mathrm{an}}(x)-I \cdot R_{\mathrm{cell}}+\left(T-T_{\mathrm{Ref}}\right) \cdot \frac{\mathrm{d} U}{\mathrm{~d} T}
$$

where $V_{\mathrm{mdl}}$ is the voltage output of the model, $U_{\mathrm{ca}}(y)$ is the cathode potential, $U_{\text {an }}(x)$ the anode potential. $I$ is the current. $I=5 \mathrm{~A}$ for discharge test, whereas $I$ is the current for ISC during high temperature test, because there is no external load. $R_{\text {cell }}$ is the average ohmic resistance of the battery throughout the discharge process, $T$ is the temperature,
$T_{\text {Ref }}=25^{\circ} \mathrm{C}$ is the reference temperature, $\frac{\mathrm{d} U}{\mathrm{~d} T}=-0.0001 \mathrm{~V}$ is the entropic coefficient to fit the voltage depleting for $T<80^{\circ} \mathrm{C}$.

$U_{\mathrm{ca}}(y)$ and $U_{\mathrm{an}}(x)$ vary with the state-of-charge (SOC) of the cathode and the anode, $y$ and $x$, respectively. The functional relations for $U_{\text {ca }}$ and $U_{\text {an }}$ are measured from half-cell test, as in Ref. 67 and shown in Figure 1. Note that $y$ and $x$ are the SOC in the half-cell test, not the $\mathrm{y}$ in $\mathrm{Li}_{y}\left(\mathrm{Ni}_{\alpha} \mathrm{Co}_{\beta} \mathrm{Mn}_{\gamma}\right) \mathrm{O}_{2}$ or the $x$ in $\mathrm{Li}_{x} \mathrm{C}_{6}$. At the beginning of discharge, the cathode is at its low SOC $(y \rightarrow 0)$ and the anode in its high SOC $(x \rightarrow 1)$. As the discharge process goes on, $y$ and $x$ change proportionally to the current $I$ according to Eqs. 2 and 3:

$$
\begin{aligned}
& y=y_{0}+\eta \cdot \int_{0}^{t} \frac{I}{Q_{\mathrm{ca}}} \mathrm{d} \tau \\
& x=x_{0}-\eta \cdot \int_{0}^{t} \frac{I}{Q_{\mathrm{an}}} \mathrm{d} \tau
\end{aligned}
$$

where $Q_{\text {ca }}$ and $Q_{\text {an }}$ are the available capacity for the cathode and anode, respectively. $\eta$ is the columbic efficiency, $\eta=1$ especially for lithium-ion batteries. $y_{0}$ and $x_{0}$ denote the initial value for $\left.y\right|_{t=0}$ and $\left.x\right|_{t=0}$ in the discharge process, respectively. $y_{\text {end }}$ and $x_{\text {end }}$ denote the value for $y$ and $x$ at the termination of discharge, respectively. The values of $\left\{y_{0}, x_{0}, Q_{\text {ca }}, Q_{\text {an }}, R_{\text {cell }}\right\}$, as shown in Figure 1 , are identified using genetic algorithm with a cost function considering root mean square error, as in Ref. 36. Some of the parameters can be referred from Ref. 67 with minor revisions to fit the experimental data of a specific cell used in this paper.

Note that there is no load across the cell during the validation tests using accelerating rate calorimetry(ARC), therefore the electrochemical-thermal effect of heat generation is not considered in the electrochemical model. The parameters $\left\{y, x, Q_{\text {ca }}, Q_{\text {an }}, R_{\text {cell }}\right\}$ in the electrochemical model directly link to the degradation forms of LLI, LAM and ORI. The correlated dynamics are further built as follows.

The degradation model under high temperature.-The coupled electrochemical-thermal processes related with SEI decomposition and regeneration.- - In 2014, Tanaka and Bessler ${ }^{38}$ pointed out that the decomposition and regeneration of SEI occur simultaneously at high temperature for lithium-ion cells. A similar phenomenon was discussed by Richard and Dahn ${ }^{37}$ fifteen years ago. Here we reformulate the correlated mechanisms in Figure 2, trying to make the complex process more clear. Figure 2a shows the original state at the surface of the graphite anode, with compact SEI protecting the intercalated lithium from electrolyte.

\section{(1) SEI decomposition}

Figure $2 \mathrm{~b}$ shows that once the temperature rises higher than the decomposition temperature ( $\left.T_{\text {onset,SEI }}\right)$, the decomposition of SEI initiates with the reaction kinetics calculated by Arrhenius Equation as Eq. 4:

$$
\frac{\mathrm{d} c_{\mathrm{SEI}}^{\mathrm{d}}}{\mathrm{d} t}=A_{\mathrm{SEI}} \cdot c_{\mathrm{SEI}} \cdot \exp \left(-\frac{E_{\mathrm{a}, \mathrm{SEI}}}{R^{0} \cdot T}\right)\left(T>T_{\text {onset,SEI }}\right)
$$

where $\frac{\mathrm{d} c_{\mathrm{SEI}}^{\mathrm{d}}}{\mathrm{d} t}$ refers to the decomposition rate of SEI, $A_{\mathrm{SEI}}$ is the preexponential factor, $c_{\mathrm{SEI}}$ is the normalized concentration of SEI, $E_{a, \mathrm{SEI}}$ is the activation energy, $R^{0}=8.314 \mathrm{~J} \cdot \mathrm{mol}^{-1} \cdot \mathrm{K}^{-1}$ is the molar gas constant, $T$ is temperature in the model. The parameters related with Arrhenius Equations are collected in Table II.

\section{(2) Li reacts with electrolyte at the anode interface}

The intercalated lithium in the anode reacts with the electrolyte, when the SEI breaks down, as shown in Figure 2b. Such a reaction generates heat, of which the amount can be measured by DSC. ${ }^{58,68}$ 
(a) Original state

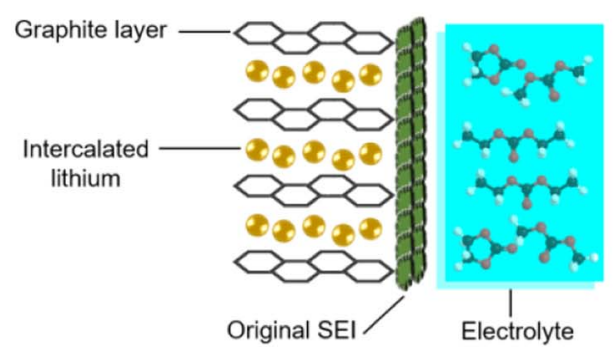

(b) SEI decomposition

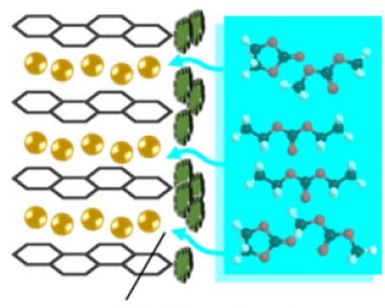

Li \& Electrolyte Contact (c) SEI regeneration

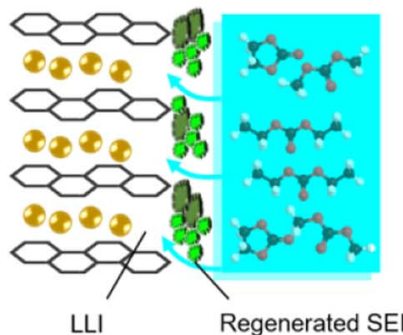

Figure 2. Coupled electrochemical-thermal processes that cause SEI decomposition and regeneration at extreme high temperature, usually higher than $60^{\circ} \mathrm{C}$.

The reaction is modeled by a modified Arrhenius Equation as in Eq. 5:

$$
\begin{aligned}
\frac{\mathrm{d} c_{\text {anode }}^{\mathrm{d}}}{\mathrm{d} t}= & A_{\text {anode }} \cdot c_{\text {anode }} \cdot \exp \left(-\frac{E_{a, \text { anode }}}{R^{0} \cdot T}\right) \\
& \cdot \exp \left(-\frac{c_{\text {SEI }}}{c_{\text {SEI }, 0}^{\text {ref }}}\right)\left(T>T_{\text {onset,anode }}\right)
\end{aligned}
$$

where $\frac{\mathrm{d} c_{\text {anode }}^{\mathrm{d}}}{\mathrm{d} t}$ means the rate for the reaction between the intercalated lithium and the electrolyte, $A_{\text {anode }}$ is the pre-exponential factor, $c_{\text {anode }}$ is the normalized concentration of full reaction between the anode and the electrolyte, $E_{a \text {,anode }}$ is the activation energy. The parameters related with Arrhenius Equations are listed in Table II. $\exp \left(-\frac{c_{\mathrm{SEI}}}{c_{\mathrm{SEI}, 0}}\right)^{59,60}$ is a correlation factor used to modify the reaction rate, taking into account that the thicker the SEI layer is, the slower the reaction will be.

The reaction between the intercalated lithium and the electrolyte is like the "formation" process to form SEI layer on the surface of anode during manufacturing. The formation of new SEI layer is called as the regeneration of SEI, as shown in Figure 2c.

\section{(3) Loss of lithium inventory}

The SEI regeneration at high temperature will definitely cause LLI. $\kappa_{\mathrm{LLI}}$, the rate of LLI, is regarded as proportional to $\frac{\mathrm{d} c_{\text {anode }}^{\mathrm{d}}}{\mathrm{d} t}$ as in Eq. 6:

$$
\kappa_{\mathrm{LLI}}=K_{\mathrm{LLI}} \cdot \frac{\mathrm{d} c_{\text {anode }}^{\mathrm{d}}}{\mathrm{d} t}
$$

where $K_{\mathrm{LLI}}=2.7$ is used to fit the heat generation data. Furthermore, $\Delta x_{\mathrm{LLI}}$, which is the total LLI caused by SEI regeneration can be modeled by Eq. 7:

$$
\Delta x_{\mathrm{LLI}}=\int_{0}^{t} \kappa_{\mathrm{LLI}} \mathrm{d} \tau
$$

Consequently, the $x_{0}$ in Eq. 3 will decrease by $\Delta x_{\mathrm{LLI}}$ from its original $x_{0,0}$, as in Eq. 8 .

$$
x_{0}=x_{0,0}-\Delta x_{\mathrm{LLI}}
$$

\section{(4) SEI regeneration}

Eq. 9 forms the direct proportional relationship between the SEI regeneration and the reaction between anode and electrolyte. $\frac{\mathrm{d} g_{\text {SEI }}^{\mathrm{g}}}{\mathrm{d} t}$ is the regeneration rate of the SEI layer, $K_{\mathrm{SEI}}^{\mathrm{g}}$ is the constant factor for the SEI regeneration, $K_{\mathrm{SEI}}^{\mathrm{g}}=6$ to fit the experimental data, and the settings of $K_{\mathrm{SEI}}^{\mathrm{g}}$ is discussed in the section of modeling analysis, $\frac{\mathrm{d} c c_{\text {anode }}^{\mathrm{d}}}{\mathrm{d} t}$ is modeled by Eq. 5 .

$$
\frac{\mathrm{d} c_{\mathrm{SEI}}^{\mathrm{g}}}{\mathrm{d} t}=K_{\mathrm{SEI}}^{\mathrm{g}} \cdot \frac{\mathrm{d} c_{\text {anode }}^{\mathrm{d}}}{\mathrm{d} t}
$$

The net change of the $c_{\mathrm{SEI}}$, which also represents the thickness of the SEI layer, is defined as $\kappa_{\mathrm{SEI}}$ in Eq. 10 . The $c_{\mathrm{SEI}}$ can thus be calculated by Eq. 11 .

$$
\begin{gathered}
\kappa_{\mathrm{SEI}}=\frac{\mathrm{d} c_{\mathrm{SEI}}}{\mathrm{d} t}=\frac{\mathrm{d} c_{\mathrm{SEI}}^{\mathrm{d}}}{\mathrm{d} t}-\frac{\mathrm{d} c_{\mathrm{SEI}}^{\mathrm{g}}}{\mathrm{d} t} \\
c_{\mathrm{SEI}}=c_{\mathrm{SEI}, 0}-\int_{0}^{t} \kappa_{\mathrm{SEI}} \mathrm{d} \tau
\end{gathered}
$$

(5) Resistance growth

The growth of SEI layer will cause an increase in the cell resistance. The increasing rate of the cell resistance caused by SEI regeneration is defined in Eq. 12: ${ }^{36}$

$$
\kappa_{R}=K_{R} \cdot \kappa_{\mathrm{LLI}}
$$

where $\kappa_{\mathrm{R}}$ is the increasing rate of the cell resistance, and $K_{\mathrm{R}}=0.074$ links $\kappa_{\mathrm{R}}$ and $\kappa_{\mathrm{LLI}}$. Furthermore, the increment in the cell resistance $\left(\Delta R_{\mathrm{SEI}}\right)$ can be integrated by Eq. 13.

$$
\Delta R_{\mathrm{SEI}}=\int_{0}^{t} \kappa_{R} \cdot \mathrm{d} \tau
$$

Resistance growth of the cell.-The increase of cell resistance not only includes the increment caused by SEI growth $\left(\Delta R_{\mathrm{SEI}}\right)$, but also contains the increment caused by separator melting $\left(\Delta R_{\text {sep }}\right)$ and electrolyte vaporization $\left(\Delta R_{\text {ele }}\right)$. The $R_{\text {cell }}$ can thus be modeled by Eq. 14:

$$
R_{\text {cell }}=\left(R_{\text {cell }, 0}+\Delta R_{\mathrm{SEI}}+\Delta R_{\text {sep }}+\Delta R_{\text {ele }}\right) \cdot \xi(T)
$$

where $R_{\text {cell, } 0}$ is the initial value of $R_{\text {cell }}$ at $25^{\circ} \mathrm{C}, \xi(T)$ is function that compensates the resistance decrease caused by temperature rise. According to the test results as shown in Figure 3, $\xi(T)$ is given by Eq. 15:

$$
\xi(T)=\exp \left(\frac{T_{\xi}}{T}\right)-b_{\xi}
$$

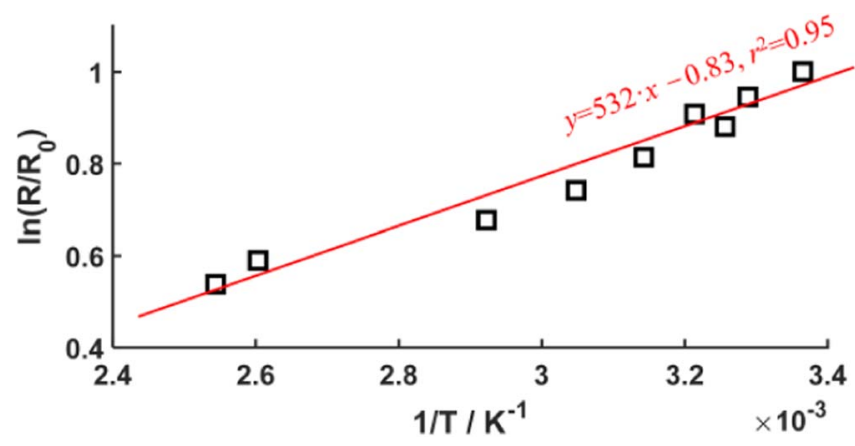

Figure 3. The relationship between resistance and temperature, $\xi(T)$. 
(a)

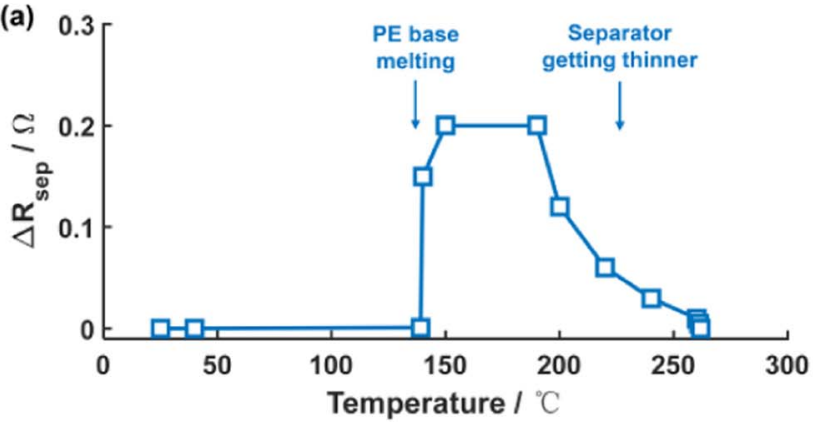

(b)

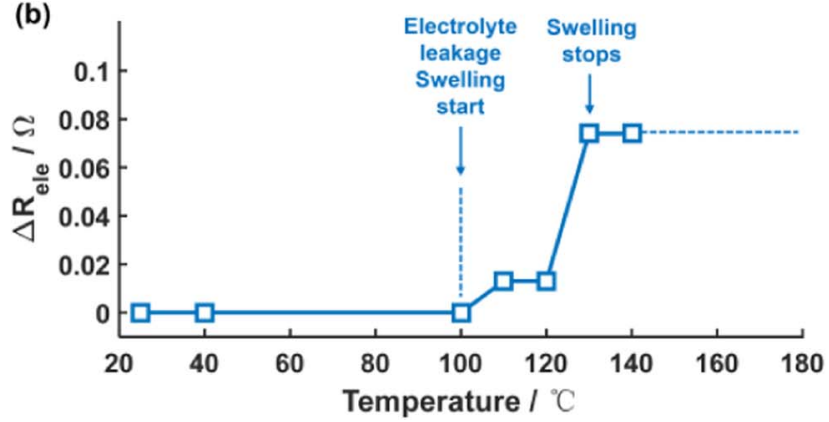

Figure 4. Parameter settings of the increments in resistance in the electrochemical model. (a) $\Delta R_{\mathrm{sep}}$, (b) $\Delta R_{\text {ele }}$.

where $T_{\xi}=523 \mathrm{~K}$ is the constant that sets a reference temperature, $b_{\xi}=$ 0.83 is an offset factor that is calibrated from the linear interpolation in Figure 3. $\Delta R_{\text {sep }}$ and $\Delta R_{\text {ele }}$ have physical meanings as shown in Figure 4. $\Delta R_{\text {sep }}$ does not increase until the temperature reaches the melting point of the PE base (the separator of the cell has PE base with ceramic coating). The $\Delta R_{\text {sep }}$ drops after the temperature reaches $200^{\circ} \mathrm{C}$ or higher, because the separator starts to get thinner and thinner as temperature rises, as shown in Figure $4 \mathrm{a} . \Delta R_{\text {ele }}$ starts to rise at around $100^{\circ} \mathrm{C}$, because the DMC (boiling point $91^{\circ} \mathrm{C}$ ) in the ternary electrolyte $\left(1 \mathrm{M} \mathrm{LiPF}_{6} \& \mathrm{DMC}: \mathrm{DEC}: \mathrm{EC}=1: 1: 1\right)$ starts to vaporize, ${ }^{69}$ as shown in Figure 5. The vaporization of solvent leads to swelling of the cell, thereby increasing the cell resistance. The swelling stops at around $130^{\circ} \mathrm{C}$, which is higher than the boiling point of DEC (boiling point $128^{\circ} \mathrm{C}$ ). $\Delta R_{\text {sep }}$ and $\Delta R_{\text {ele }}$ are set as lookup table in the model to fit the experimental results, as shown in Figure 4.

Loss of active material at the anode and cathode.-The LAM at the anode and cathode is regarded to be dominated by the leakage of the ternary electrolyte, which brings deactivation of some regions on the porous electrodes, as shown in Figure 5. The leakage of electrolyte, often occurring between $100^{\circ} \mathrm{C}-130^{\circ} \mathrm{C}$ as shown in Figure $5 \mathrm{~b}$, can be inferred from the temperature results, as shown in Figure $5 \mathrm{~d}$. The LAM of the anode and cathode are described by Eq. 16 and 17:

$$
\begin{aligned}
& Q_{\mathrm{ca}}=c_{\mathrm{LAM}, \mathrm{ca}} \cdot Q_{\mathrm{ca}, 0} \\
& Q_{\mathrm{an}}=c_{\mathrm{LAM}, \text { an }} \cdot Q_{\mathrm{an}, 0}
\end{aligned}
$$

where $c_{\mathrm{LAM}, \mathrm{ca}}$ and $c_{\mathrm{LAM}, \text { an }}$ are the normalized concentration indicating the degree of LAM at high temperature for cathode and anode respectively. Both $c_{\mathrm{LAM}, \mathrm{ca}}$ and $c_{\mathrm{LAM}, \text { an }}$ drop from 1 to a lower level larger than $0 . Q_{\mathrm{ca}, 0}=27.3 \mathrm{Ah}$ and $Q_{\mathrm{an}, 0}=32.2 \mathrm{Ah}$ are the original capacity of the cell before LAM. Assume that the LAM of the anode is mainly controlled by the electrolyte leakage, using a variable named $c_{\text {LAM,ele }}$ in the model, as in Eq. 18. The LAM of the cathode is not only controlled by $c_{\text {LAM,ele }}$, but also influenced by the dissolution of transition metal, ${ }^{30,70}$ which is marked by $c_{\mathrm{LAM}, \mathrm{dis}}^{\text {diss }}$ as in Eq. 19.

$$
\begin{gathered}
c_{\mathrm{LAM}, \mathrm{an}}=c_{\mathrm{LAM}, \mathrm{ele}} \\
c_{\mathrm{LAM}, \mathrm{ca}}=c_{\mathrm{LAM}, \mathrm{ca}}^{\text {diss }} \cdot c_{\mathrm{LAM}, \mathrm{ele}}
\end{gathered}
$$

(a) $\mathrm{T}<100^{\circ} \mathrm{C}, c_{\text {LAM,ele }}=1$

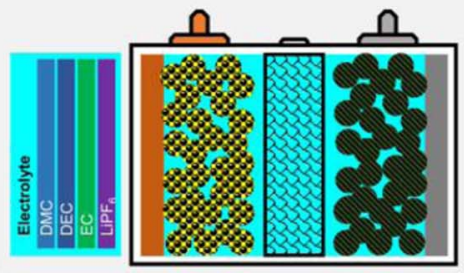

(b) $100^{\circ} \mathrm{C}<T<130^{\circ} \mathrm{C}, 1 / 3<c_{\text {LAM, ele }}<1$

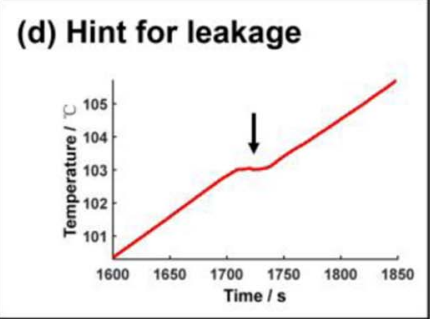

(e)

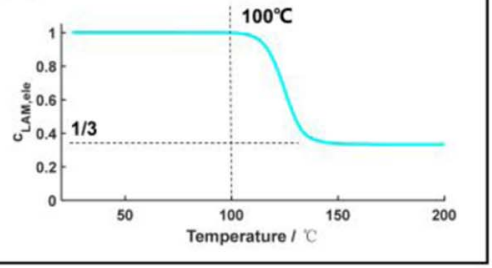

(c) After vaporization, $c_{\text {LAM,ele }}=1 / 3$
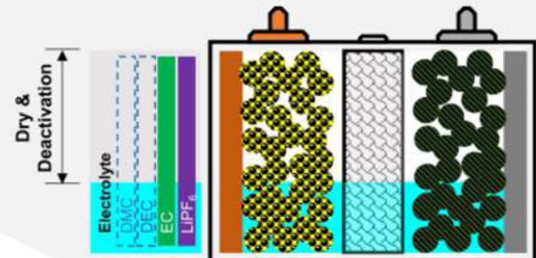

Figure 5. Loss of active material (LAM) caused by electrolyte leakage. (a) Before leakage, (b) During leakage, (c) After fully vaporization, (d) Hint for leakage from temperature drops during test, (e) Kinetics of the vaporization of the electrolyte set in the model. 
Table I. The kinetic parameters for capacity degradation caused by electrode drying.

$$
\begin{aligned}
& \text { Variable } \\
& \text { Update function } \\
& c_{\text {LAM,ele }}=c_{\text {LAM,ele }, 0}+\int_{0}^{t} \kappa_{\text {LAM,ele }} \cdot \mathrm{d} \tau \\
& c_{\mathrm{LAM}, \mathrm{ca}}^{\text {diss }}=c_{\mathrm{LAM}, \mathrm{ca}, 0}^{\text {diss }}+\int_{0}^{t} \kappa_{\mathrm{LAM}, \mathrm{ca}}^{\text {diss }} \cdot \mathrm{d} \tau \\
& \kappa_{\mathrm{LAM}, \mathrm{ca}}^{\mathrm{diss}}=\frac{\mathrm{d} c_{\mathrm{LAM}, \mathrm{ca}}^{\text {diss }}}{\mathrm{d} t}=-A_{\mathrm{LAM}, \mathrm{ca}} \cdot\left(c_{\mathrm{LAM}, \mathrm{ca}}^{\text {diss }}\right)^{2} \cdot \exp \left(-\frac{E_{a, \mathrm{LAM}, \mathrm{ca}}}{R^{0} \cdot T}\right)
\end{aligned}
$$

where $\kappa_{\mathrm{LAM}, \mathrm{ca}}^{\text {diss }}=\frac{\mathrm{d} c_{\mathrm{LAM}, \mathrm{ca}}^{\mathrm{diss}}}{\mathrm{d} t}$ is the dissolution rate, $A_{\mathrm{LAM}, \mathrm{ca}}$ is the preexponential factor, $E_{a, \mathrm{LAM}, \mathrm{ca}}^{\mathrm{d} t}$ is the activation energy. The parameters related with Arrhenius Equations are listed in Table I.

Eq. 21 is established to simulate the LAM caused by the leakage of electrolyte:

$$
\begin{aligned}
\kappa_{\mathrm{LAM}, \text { ele }} & =\frac{\mathrm{d} c_{\mathrm{LAM}, \text { ele }}}{\mathrm{d} t} \\
& =-A_{\mathrm{LAM}, \mathrm{ele}} \cdot\left(c_{\mathrm{LAM}, \mathrm{ele}}-\frac{1}{3}\right)^{2} \cdot \exp \left(-\frac{E_{a, \mathrm{LAM}, \mathrm{ele}}}{R^{0} \cdot T}\right)[21]
\end{aligned}
$$

where $\kappa_{\mathrm{LAM}, \text { ele }}=\frac{\mathrm{d} c_{\mathrm{LAM}, \text { ele }}}{\mathrm{d} t}$ is the rate of vaporization, $A_{\mathrm{LAM}, \text { ele }}$ is the preexponential factor, $E_{a, \mathrm{LAM}, \mathrm{ele}}^{\mathrm{d} t}$ is the activation energy. The parameters related with Arrhenius Equations are listed in Table I. The offset 1/3 in Eq. 21 can regulate the final value of $c_{\text {LAM,ele }}$ to be larger than $1 / 3$, because EC does not gasify until the temperature reaches its boiling point at $248^{\circ} \mathrm{C} .{ }^{69}$ Finally, Table I lists the correlated dynamics that are used to model the LAM at the cathode and anode.

Internal short circuit under extreme high temperature.-Figure 6a displays an equivalent circuit representation of the cell during ISC. The short circuit current can be calculated using Eq. 22:

$$
I=\frac{V_{\mathrm{mdl}}}{R_{\mathrm{ISC}}}
$$

where $V_{\mathrm{mdl}}$ is the voltage calculated by Eq. $1, R_{\mathrm{ISC}}$ is the equivalent resistance for the ISC. Figure $6 \mathrm{~b}$ shows the value of $R_{\mathrm{ISC}}$ that is set in the model. The variation of $R_{\mathrm{ISC}}$ encounters four stages: 1) the self-discharge at high temperature between $50-140^{\circ} \mathrm{C}$; 2) the increase caused by the melting of PE base of the separator; 3) the decrease caused by the thickness decreasing of the separator; 4) hard ISC at a critical temperature $T_{\mathrm{ISC}}^{*}$. The critical $R_{\mathrm{ISC}}$ that reflects
Initial value

$A / \mathrm{s}^{-1}$

$E_{\mathrm{a}} / \mathrm{kJ}$

$\begin{array}{llc}c_{\mathrm{LAM}, \mathrm{ele}, 0}=1 & 5 \times 10^{35} & 3 \times 10^{5} \\ c_{\mathrm{LAM}, \mathrm{ca}}^{\text {diss }}=1 & 4 \times 10^{4} & 15 \times 10^{-1}\end{array}$

the degree of hard ISC is marked as $R_{\mathrm{ISC}}^{*}$ as shown in Figure $6 \mathrm{~b}$. $T_{\mathrm{ISC}}^{*}=250^{\circ} \mathrm{C}, R_{\mathrm{ISC}}^{*}=0.01 \Omega$ in this model.

Heat generation due to the ISC is modeled by Joule heating as shown in Eq. 23:

$$
Q_{\mathrm{ISC}}=\varsigma \cdot I^{2} \cdot\left(R_{\mathrm{cell}}+R_{\mathrm{ISC}}\right)
$$

where $Q_{\text {ISC }}$ is the heat generation power of ISC, $\zeta=0.28$ is the efficacy coefficient, which is proposed in Ref. 17 to fix the non-ohmic heat generation, $I$ is the ISC current as in Eq. $22, R_{\text {cell }}$ the resistance of the cell as in Eq. 14, $R_{\mathrm{ISC}}$ is the equivalent ISC resistance as in Figure $6 \mathrm{~b}$.

Thermal model.-The thermal model is built to predict the temperature rise during the TR process. ${ }^{60}$ The temperature $T$ is modeled using Eq. 24. The derivative of $T$, i.e., $\frac{\mathrm{d} T}{\mathrm{~d} t}$, satisfies Eq. 25 according to the Energy Balance. In Eq. 25, $Q$ is the total power of heat generation, $M=720 \mathrm{~g}$ is the mass of the cell; $C_{p}=1100 \mathrm{~J} \cdot \mathrm{kg}^{-1} \cdot \mathrm{K}^{-1}$ is the specific heat capacity of the cell. The specific heat capacity $C_{p}$ was measured before TR test using ARC, and similar values can be seen in Ref. 71.

$$
\begin{gathered}
T=T_{0}+\int_{0}^{t} \frac{\mathrm{d} T}{\mathrm{~d} \tau} \mathrm{d} \tau \\
\frac{\mathrm{d} T}{\mathrm{~d} t}=\frac{Q}{M \cdot C_{p}}
\end{gathered}
$$

$Q$ is the sum of all kinds of heat generation/dissipation terms, as in shown Eq. 26:

$$
Q=Q_{\text {chem }}+Q_{\text {ISC }}-Q_{\text {dis }}
$$

where $Q_{\text {chem }}$ represents the heat generation power by chemical reactions, $Q_{\text {ISC }}$ represents the heat release power generated by ISC, and $Q_{\text {dis }}$ represents the heat transfer/dissipation power into the environment. The ARC can provide an adiabatic environment during test, therefore we can set $Q_{\text {dis }}=0$ in the model. $Q_{\text {chem }}$ can be calculated using Eq. 27, where $Q_{z}$ denotes the power in watts dissipated as heat by an arbitrary reaction $z$. $z$ can be $\{$ SEI, anode, separator, cathode, 1 , cathode,2, electrolyte $\}$ as listed in Table II. The decomposition of (a)

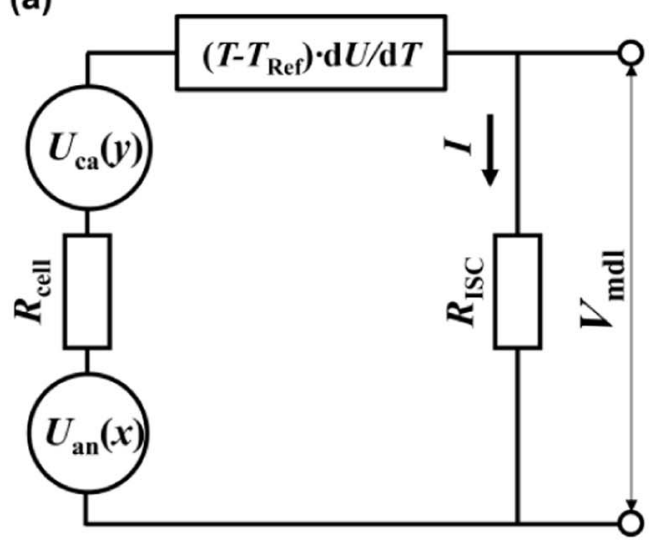

(b)

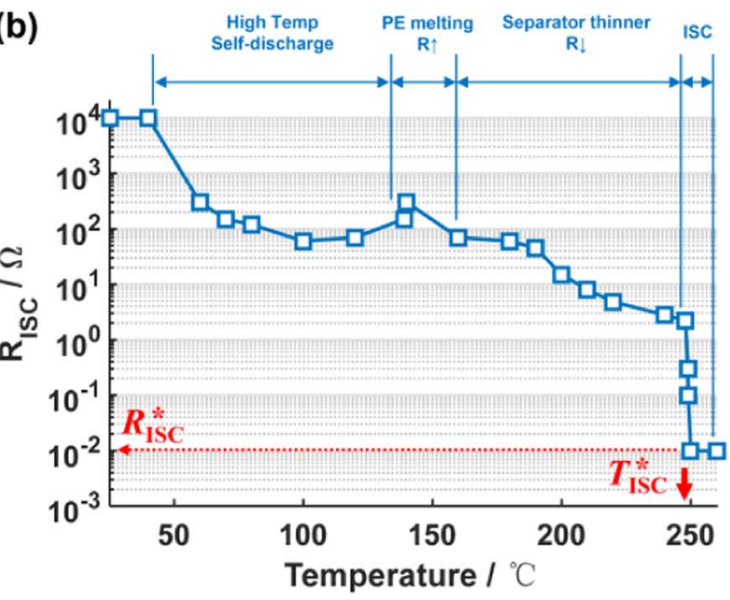

Figure 6. The settings of ISC in the model. (a) The equivalent circuit model of the ISC, (b) The $R_{\text {ISC }}$ set in the model. 
Table II. Reaction kinetics for the components of the lithium-ion cell ${ }^{\mathrm{a}}$.

\begin{tabular}{|c|c|c|c|c|c|}
\hline$z$ & $\Delta h_{z} / \mathrm{J} \cdot \mathrm{g}^{-1}$ & $m_{z} / \mathrm{g}$ & $c_{z, 0}$ & $n_{z, 1}$ & $n_{z, 2}$ \\
\hline SEI & $150^{*}$ & 100.58 & 0.15 & 1 & 0 \\
\hline anode & 1714 & 100.58 & 1 & 1 & 0 \\
\hline separator & -190 & 17.6 & 1 & 1 & 0 \\
\hline cathode, 1 & 77 & 179.12 & 0.999 & 1 & 1 \\
\hline cathode, 2 & 84 & 179.12 & 0.999 & 1 & 1 \\
\hline electrolyte & 800 & 108 & 1 & 1 & 0 \\
\hline$z$ & $T_{\text {onset }, z} /{ }^{\circ} \mathrm{C}$ & $A_{z} / \mathrm{s}^{-1}$ & $E_{a, z} / \mathrm{J} \cdot \mathrm{mol}-1$ & $\frac{\mathrm{d} c_{z}^{g}}{\mathrm{~d} t}$ & $g_{z}$ \\
\hline $\begin{array}{c}\text { SEI } \\
\text { anode }\end{array}$ & $\begin{array}{l}50 \\
50\end{array}$ & $\begin{array}{c}1.667 \times 10^{15} \\
0.038^{*}(T<260) 5(T>260)\end{array}$ & $\begin{array}{c}1.3508 \times 10^{5} \\
3.3 \times 10^{4}\end{array}$ & $K_{\mathrm{SEI}}^{\mathrm{g}} \cdot \frac{\mathrm{d} c_{\text {anode }}^{\mathrm{d}}}{\mathrm{d} t}$ & $\begin{array}{c}1 \\
\exp \left(-\frac{c_{\mathrm{SEEI}}(t)}{c_{\mathrm{SEI}}^{\text {ref }}}\right)\end{array}$ \\
\hline separator & 120 & $1.5 \times 10^{50}$ & $4.2 \times 10^{5}$ & 0 & $1^{\text {SEI,0 }}$ \\
\hline cathode, 1 & 180 & $1.75 \times 10^{9}$ & $1.1495 \times 10^{5}$ & 0 & 1 \\
\hline cathode, 2 & 220 & $1.077 \times 10^{12}$ & $1.5888 \times 10^{5}$ & 0 & 1 \\
\hline electrolyte & $120^{*}$ & $1.5 \times 10^{13 *}$ & $1.5 \times 10^{5 *}$ & 0 & 1 \\
\hline
\end{tabular}

aParameters without superscript come from Ref. 60. Parameters with * superscript are adjusted from Ref. 60 to fit the experimental data.

the $\mathrm{Li}(\mathrm{NiCoMn})_{1 / 3} \mathrm{O}_{2}$ cathode includes two exothermic reactions, ${ }^{72}$ the chemical kinetics of which have been calibrated by Kissinger's method as in Ref. 73. Successful practice in the modeling of full cell's TR behavior can be seen in Ref. 60 .

$$
Q_{\text {chem }}=\sum_{z} Q_{z}+Q_{\mathrm{Ca}+\mathrm{An}}
$$

The heat generation rate $Q_{z}$ is proportional to the decomposition rate $\left(\frac{\mathrm{d} \mathrm{c}_{z}^{\mathrm{d}}}{\mathrm{d} t}\right)$ of the normalized concentration $\left(c_{z}\right)$ of reactant in reaction $z$, as shown in Eq. 28. $\Delta h_{z}$ is the enthalpy of the chemical reaction $z$; $m_{z}$ is the total mass of the reactants inside the cell; $T_{\text {onset }, z}$ is the onset temperature of the reaction $z$. The determinant condition, $T>T_{\text {onset, } z}$ within the bracket implies that the reaction $z$ only happens when the $T$ is higher than $T_{\text {onset }, z}$.

$$
Q_{z}=\Delta h_{z} \cdot m_{z} \cdot \frac{\mathrm{d} c_{z}^{\mathrm{d}}}{\mathrm{d} t},\left(T>T_{\text {onset }, z}\right)
$$

$c_{z}$ can be integrated from its derivative $\frac{\mathrm{d} c_{z}}{\mathrm{~d} t}$, as shown in Eq. 29, where $c_{z, 0}$ represents the initial value of $c_{z}, \kappa_{z}$ is a proportionality factor, $\frac{\mathrm{d} c_{z}}{\mathrm{~d} t}$ equals the difference between the decomposition rate $\frac{\mathrm{d} c_{z}^{\mathrm{d}}(t)}{\mathrm{d} t}$ and the regeneration rate $\frac{\mathrm{d} c_{z}^{\mathrm{g}}(t)}{\mathrm{d} t}$ of reactant $z$, as shown in Eq. 30 .

$$
c_{z}=c_{z, 0}-\int_{0}^{t} \kappa_{z} \mathrm{~d} \tau
$$

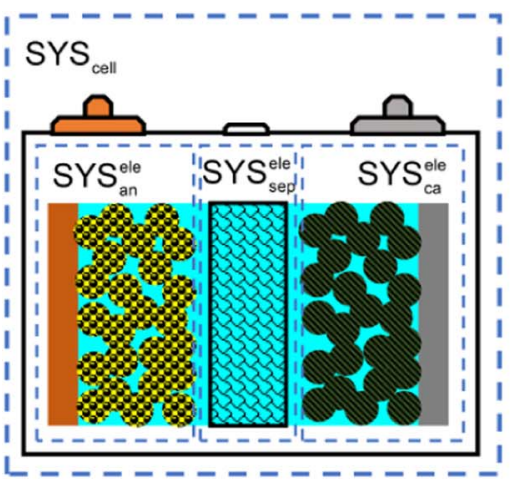

$Q_{z}$

$$
\kappa_{z}=\frac{\mathrm{d} c_{z}}{\mathrm{~d} t}=\frac{\mathrm{d} c_{z}^{\mathrm{d}}}{\mathrm{d} t}-\frac{\mathrm{d} c_{z}^{\mathrm{g}}}{\mathrm{d} t}
$$

The decomposition rate $\frac{\mathrm{d} c_{z}^{\mathrm{d}}(t)}{\mathrm{d} t}$ conforms with Arrhenius Equation as shown in Eq. 31:

$$
\frac{\mathrm{d} c_{z}^{\mathrm{d}}}{\mathrm{d} t}=A_{z} \cdot\left(c_{z}\right)^{n_{z, 1}} \cdot\left(1-c_{z}\right)^{n_{z, 2}} \cdot \exp \left(-\frac{E_{a, z}}{R^{0} \cdot T}\right) \cdot g_{z}\left(T>T_{\text {onset }, z}\right)
$$

where $A_{z}$ is the frequency factor; $n_{z, 1}$ and $n_{z, 2}$ are the orders for reaction $z ; E_{a, z}$ is the activation energy; $R^{0}=8.314 \mathrm{~J} \cdot \mathrm{mol}^{-1} \cdot \mathrm{K}^{-1}$ is the ideal gas constant; $g_{z}$ is the correction term of specific reaction. The values of the parameters that are related to chemical kinetics and have $z$ as subscripts have been listed in Table II.

The $Q_{\mathrm{Ca}+\mathrm{An}}$ in Eq. 27 denotes the rapid oxidation-reduction reaction between the cathode and anode after a TR is triggered. The rapid oxidation-reduction reaction resembles the reaction between the fuel and oxygen in a combustion reaction. ${ }^{74}$ The exact mechanism of the rapid oxidation-reduction reaction during TR is not clear, because the heat release rate is too fast. Figure 7 provides hypothesis for the reaction mechanism involving the rapid oxidation-reduction reaction. If the separator is intact, the decomposition reactions are confined within a limited spaces, which we call a reaction system (marked as $\mathrm{SYS}$ in Figure 7). The $\mathrm{SYS}_{\mathrm{ca}}^{\text {ele }}, \mathrm{SYS}_{\mathrm{sep}}^{\text {ele }}$, and $S Y \mathrm{~S}_{\text {an }}^{\text {ele }}$ react independently reflecting in the $Q_{z}$ in Eq. 27. We have sufficient knowledge on the

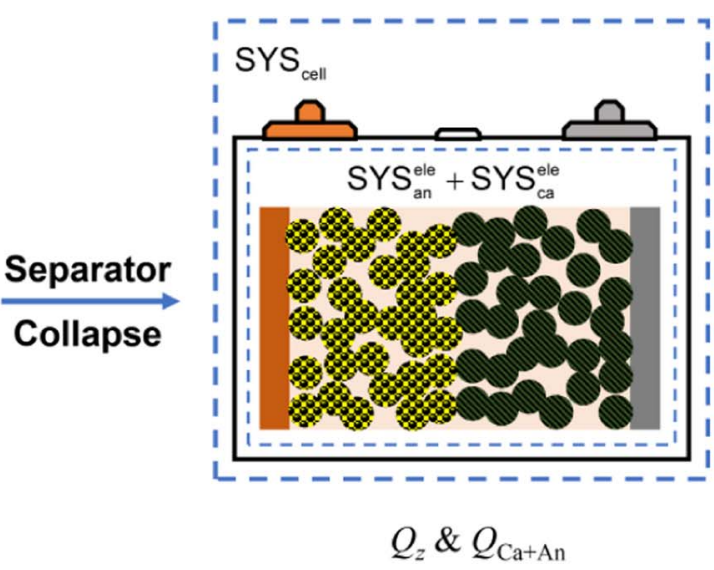

Figure 7. The fierce reaction between cathode and anode after separator collapses at extreme temperature. The symbol "SYS" means a thermodynamic system that generates heat from chemical reactions. 
(a)

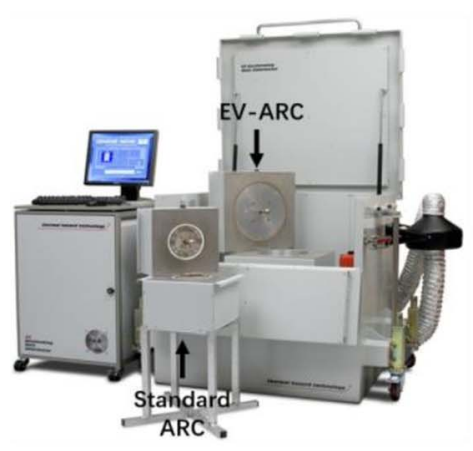

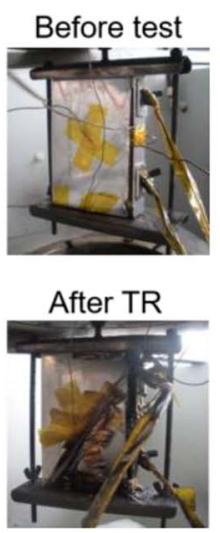

(b)

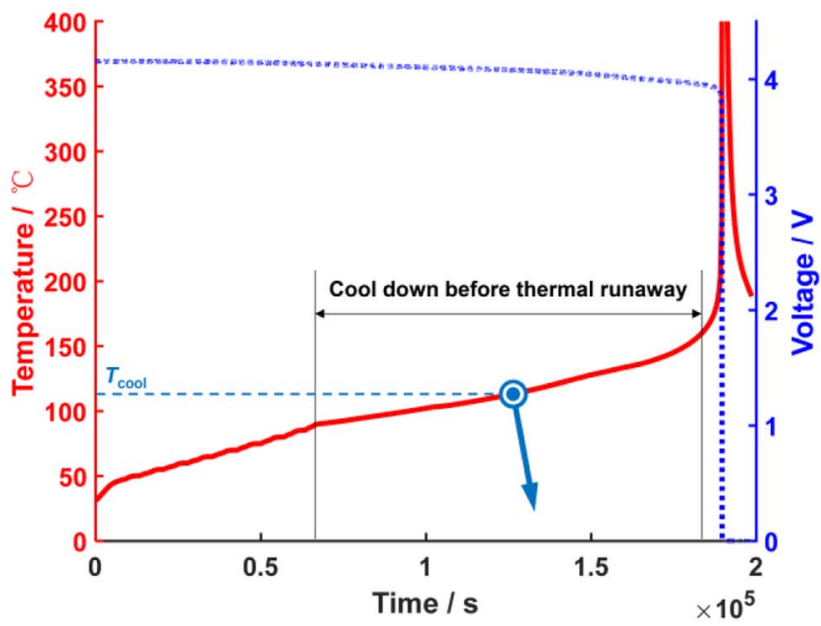

Figure 8. Experimental settings for model validation. (a) The thermal runaway test using ARC, (b) The results of a thermal runaway test, and the test with cooling before thermal runaway.

reaction kinetics of $Q_{z}$, because the reaction system is well-defined, and the heat generation can be well measured using DSC. However, once the separator collapses at extremely high temperature, the cathode and anode will come into contact with each other, forming a complex reaction system comprised of $S Y S_{\mathrm{ca}}^{\text {ele }}+\mathrm{SYS}_{\mathrm{an}}^{\text {ele }}$. The reaction of $\mathrm{SYS}_{\mathrm{ca}}^{\text {ele }}+\mathrm{SYS}_{\mathrm{an}}^{\text {ele }}$ is quite rapid as defined in Ref. 58, with an onset temperature of $\left.T_{\text {onset,Ca+An }}\right)$. Liu ${ }^{75}$ et al. believe that the oxidationreduction reaction is caused by "chemical-crosstalk" with migration of oxide material across the separator, making the case even more complex. This is a new area of active researches, and here we choose to model the system based on the assumptions shown in Figure 7 and Ref. 58.

$Q_{\mathrm{Ca}+\mathrm{An}}$ can then be calculated using Eq. 32:

$$
Q_{\mathrm{Ca}+\mathrm{An}}=\frac{1}{\Delta t} \cdot\left(\Delta H_{\mathrm{Ca}+\mathrm{An}}-\int_{0}^{t} Q_{\mathrm{Ca}+\mathrm{An}} \mathrm{d} \tau\right),\left(T>T_{\text {onset }, \mathrm{Ca}+\mathrm{An}}\right)
$$

where $\Delta H_{C a+A n}$ is the total energy released to heat the battery during the rapid oxidation-reduction reaction; $\Delta t$ is the average time for energy release, here we choose $\Delta t=10 \mathrm{~s}$ for the model based on experimental observations; and $T_{\text {onset,Ca+An }}$ is set as $260^{\circ} \mathrm{C}$ for the cell, because the cell used in our experiments has a PE-based ceramic coated separator with a collapse temperature of $260^{\circ} \mathrm{C}$ as reported in Ref. 76.

The total chemical energy released during TR process, $\Delta H$, satisfies the energy balance Equation 33:

$$
\Delta H=M \cdot C_{p} \cdot \Delta T=\Delta H_{\mathrm{chem}}+\Delta H_{\mathrm{Ca}+\mathrm{An}}+\Delta H_{\mathrm{ISC}}
$$

where $\Delta T$ represents the total temperature rise measured by ARC test; $\Delta H_{\text {chem }}$ is the total energy released by all of the chemical reactions, which is calculated by Eq. $34 ; \Delta H_{\text {ISC }}$ is the total thermal energy release by ISC, which is calculated using Eq. $35 . \Delta H_{\mathrm{Ca}+\mathrm{An}}$ is set to $308000 \mathrm{~J}$ in order to fit the $\Delta T$ in our experiments.

$$
\begin{aligned}
\Delta H_{\text {chem }} & =\sum_{z} \int_{0}^{\tau=\infty} Q_{z} \cdot \mathrm{d} \tau \\
\Delta H_{\mathrm{ISC}} & =\int_{0}^{\tau=\infty} Q_{\mathrm{ISC}} \cdot \mathrm{d} \tau
\end{aligned}
$$

\section{Experimental}

TR tests are conducted using ARC to validate the coupled electrochemical-thermal model. The ARC (Figure 8a) is manufactured by Thermal Hazard Technology. A common ARC test follows the heat-wait-seek method. ${ }^{37,74}$ The ARC with extended-volume (EVARC) can hold the cell with large format in the tests. The $25 \mathrm{Ah}$ cell employed for the ARC test is a rechargeable $\mathrm{LiNi}_{x} \mathrm{Co}_{y} \mathrm{Mn}_{z} \mathrm{O}_{2}$ polymer battery manufactured by AE Energy Co. Ltd. It has $\mathrm{LiNi}_{x} \mathrm{Co}_{y} \mathrm{Mn}_{z} \mathrm{O}_{2}$ as its cathode and graphite as its anode. The separator is polyethylene (PE) based, with a ceramic coating. The detailed material composition of the battery can be found in Ref. 67 .

The voltage and the temperature were recorded during the test, in order to validate the coupled electrochemical-thermal model. The experimental results are shown in Figure $8 \mathrm{~b}$. A unique test, which is called the TR test with early termination, ${ }^{67}$ is set up to study the degradation behavior of lithium-ion battery exposed to "near" runaway conditions. In the ARC test with early termination, the heating process was stopped once the temperature reached a pre-defined value $\left(T_{\text {cool }}\right)$, as shown in Figure $8 \mathrm{~b}$. The cell sample was pulled out of the chamber and cooled down to ambient temperature. $T_{\text {cool }}=\left\{80^{\circ} \mathrm{C}\right.$, $\left.90^{\circ} \mathrm{C}, 100^{\circ} \mathrm{C}, 110^{\circ} \mathrm{C}, 120^{\circ} \mathrm{C}, 130^{\circ} \mathrm{C}, 140^{\circ} \mathrm{C}, 160^{\circ} \mathrm{C}\right\}$ for the ARC test with early termination. The cells were discharged at $5 \mathrm{~A}(\mathrm{C} / 5$ rate) after cooling to ambient temperature. The voltage and capacity of the discharge process are used to check the performance of coupled electrochemical-thermal model in simulating the capacity degradation under extreme temperature. Further details on the ARC results can be found in Ref. 67 and. ${ }^{74}$

\section{Results and Discussion}

Model validation.-The simulation is conducted using Simulink 8.7 with code in Matlab 2016a. The solver is chosen as ode23s (stiff/Mod. Rosenbrock) with variable steps. The relative tolerance is $10^{-8}$ during simulation. The numerical solutions of Arrhenius Equations can be referred to Ref. 21. Figure 9 shows the verification results for the coupled electrochemical-thermal model. The simulation results can fit the ARC test results for the $T-t, V$ - $t$ and $V$-T profile, as shown in Figures $9 \mathrm{a}-9 \mathrm{c}$, indicating the coupled electrochemical-thermal model can predict the evolution of the voltage and the temperature well. Figure $9 \mathrm{~d}$ shows that the electrochemical-thermal coupled model can also fit the $\mathrm{d} T / \mathrm{d} t$ results well. The model has high accuracy in simulating the $\mathrm{d} T / \mathrm{d} t$ results, especially for the temperatures between $80-300^{\circ} \mathrm{C}$, as shown in Figure 9e, indicating that the model can capture the dynamics of heat generation caused by chemical reactions. 
(a)

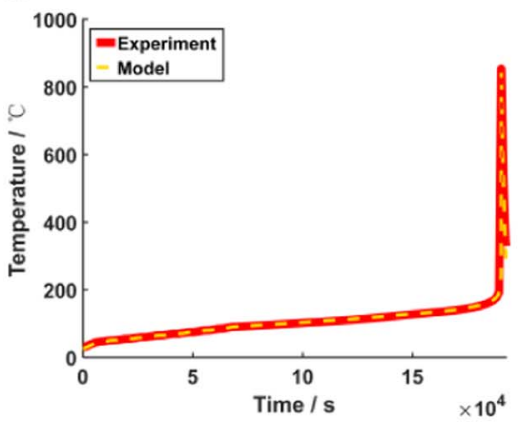

(b)

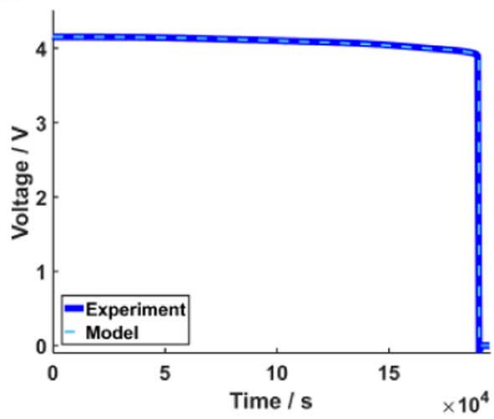

(c)

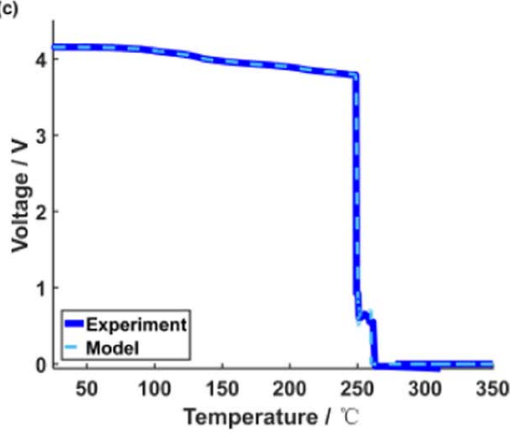

(d)

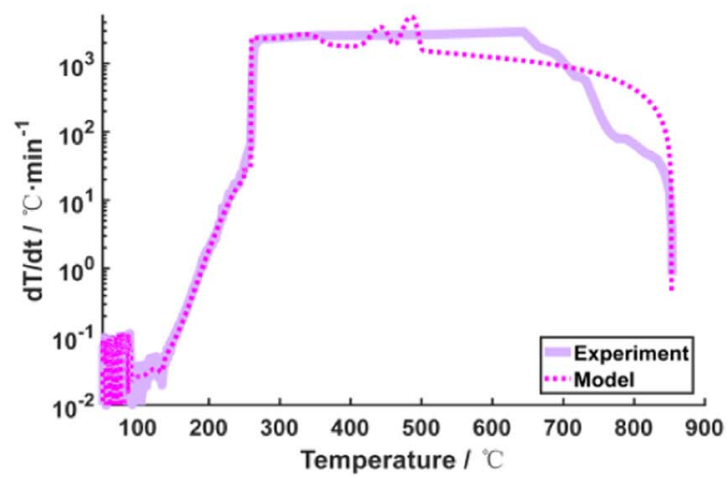

(e)

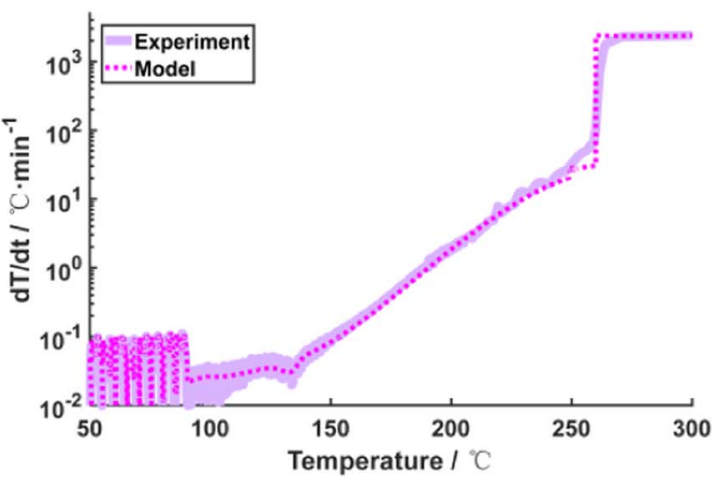

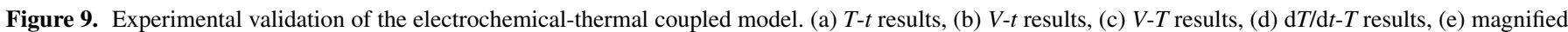
figure of (d).

Figure 10 displays the status of chemical reactions during the temperature rise. Figure 10a shows the different heat generation rates that contribute to the total heat generation in Eq. 26. The proportion of the heat generation by ISC $\left(Q_{\text {ISC }}\right)$ in the total heat generation $\left(Q_{\text {Total }}\right)$ is similar with that was reported in Ref. 77 . Figure 10b shows the normalized concentrations of different reactants. Most of the reactions occur sequentially with concentrations dropping from 1 to 0 . A special case is that the $c_{\mathrm{SEI}, 0}=0.15$ for the SEI decomposition. The increment in $c_{\text {SEI }}$ can be clearly seen in Figure $10 \mathrm{~b}$ for $60^{\circ} \mathrm{C}<T<90^{\circ} \mathrm{C}$, indicating the speed of SEI regeneration is faster than that of SEI decomposition at that time. Figure 10c presents the cumulative heat with a unit of Joule for all the heat generation terms, allowing a more rapid appreciation of the reactions that drive the temperature rise. Moreover, the percentage of individual heat generation terms in the total heat generation is summarized in Figure 10d. Interestingly, the heat generation by ISC only occupies $2 \%$ of the total heat during TR, indicating that ISC is not the major heat sources of TR.

The discharge curves of the electrochemical model fit well with that from the experiments, for all $T_{\text {cool }}$ between $80^{\circ} \mathrm{C}$ and $130^{\circ} \mathrm{C}$, as shown in Figure $11 \mathrm{a}$. For the $T_{\text {cool }}>130^{\circ} \mathrm{C}$, the cell capacity approximately drops to zero, therefore the results for $T_{\text {cool }}>130^{\circ} \mathrm{C}$ are not shown. The capacity retention rate of the model also fits well with the experimental data, as shown in Figure $11 \mathrm{~b}$, indicating that the variables in the electrochemical model can capture the real capacity degradation mechanisms at high temperature. The critical variables $\left\{y, x, Q_{\mathrm{ca}}, Q_{\mathrm{an}}, R_{\mathrm{cell}}\right\}$ are shown in Figures $11 \mathrm{c}-11 \mathrm{e}$, respectively. It can be seen that the LLI starts from $90^{\circ} \mathrm{C}$ due to SEI regeneration, whereas the LAM starts from $100^{\circ} \mathrm{C}$ due to electrolyte leakage.

We add remarks here to clarify the relationship between the concentrations that are used for electrochemical decomposition and that for thermal failure. This paper considers the "thermal $\rightarrow$ electrochemical" coupling that models the influences of the high temperature exposure on the battery capacity degradation by Eqs. 16-21. The logic flow for the "thermal $\rightarrow$ electrochemical" cou- pling should be 1) $c_{z} \rightarrow Q_{z}$ by Eqs. 28-31;2) $Q_{7} \rightarrow T$ by Eqs. 24-27; 3) $T \rightarrow c_{\text {LAM }}$ by Eqs. 18-21. Therefore, the concentrations of chemical reactions $\left(c_{\mathrm{z}}\right)$ affects the evolution of the concentrations of electrochemical decompositions $\left(c_{\text {LAM }}\right)$. A close loop was not established to describe the feedback effect of $c_{\text {LAM }}$ on the $c_{\mathrm{z}}$, because we need more data that can help to build the relationship. Correlated issues might be interesting for further study.

The good prediction of the coupled electrochemical-thermal behavior convinces us that the model has good validity, and can be used for further analysis to discuss: 1) the capacity degradation under extreme temperature; 2) the regeneration of SEI and its influence on the TR behavior; 3) the influence of the ISC on the total heat generation during TR; and 4) parameters that may influence the critical features of TR.

Modeling analysis.-The degradation under storage at extreme temperature.-The coupled electrochemical-thermal model helps study the degradation under storage at extreme temperatures. The cell is assumed to be suddenly exposed to an isothermal environment, like a thermal chamber, or another extreme environment. We wish to determine how long the cell can tolerate the high temperature storage, in order to explore the tolerance of the lithium-ion cells exposed to extreme conditions. The heat dissipation term, $Q_{\text {dis }}$, should be modified by Eq. 36:

$$
Q_{\text {dis }}=h_{\text {conv }} \cdot A_{\mathrm{S}} \cdot\left(T-T_{\text {storage }}\right)
$$

where $h_{\text {conv }}=5 \mathrm{~W} \cdot \mathrm{m}^{-2} \cdot \mathrm{K}^{-1}$ is the convection coefficient for natural convection, $A_{\mathrm{S}}$ is the total area of the cell, $T_{\text {storage }}$ is the storage temperature. $T_{\text {storage }}$ is set as $\left\{80^{\circ} \mathrm{C}, 90^{\circ} \mathrm{C}, 100^{\circ} \mathrm{C}, 110^{\circ} \mathrm{C}, 120^{\circ} \mathrm{C}, 130^{\circ} \mathrm{C}\right\}$ in the simulations. The cell does not go into TR for all the $T_{\text {storage }}$, because the heat generation is not sufficient at that temperature range, indicating that the cell has good thermal stability and can pass a hot box test. 
(a)

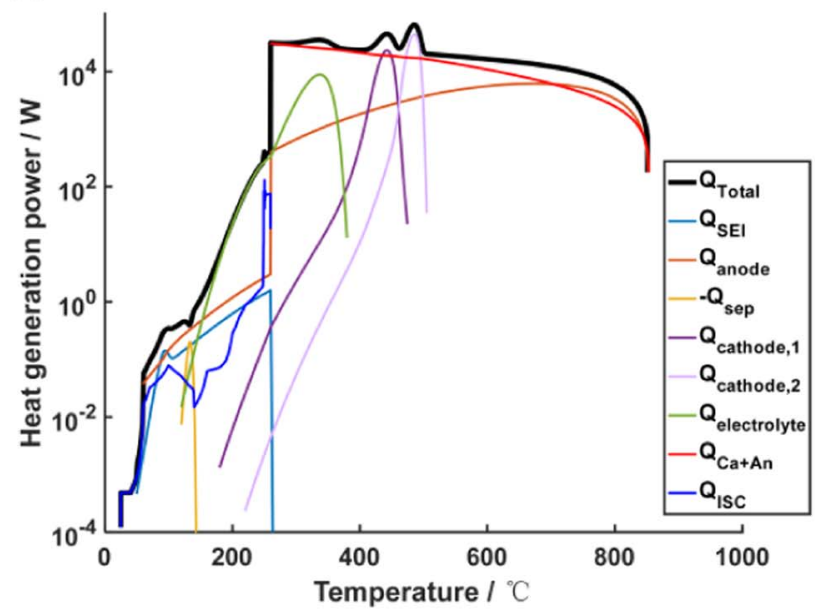

(c)

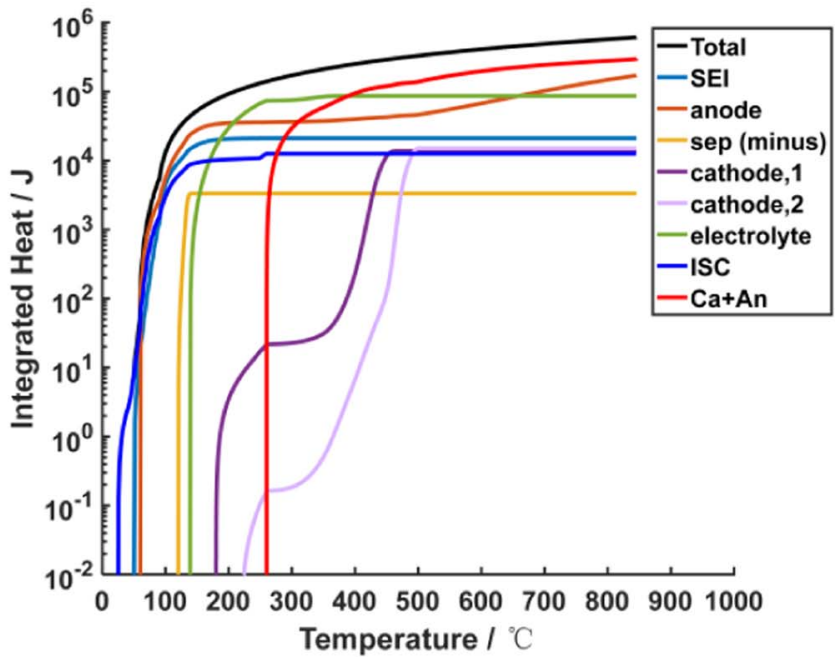

(b)

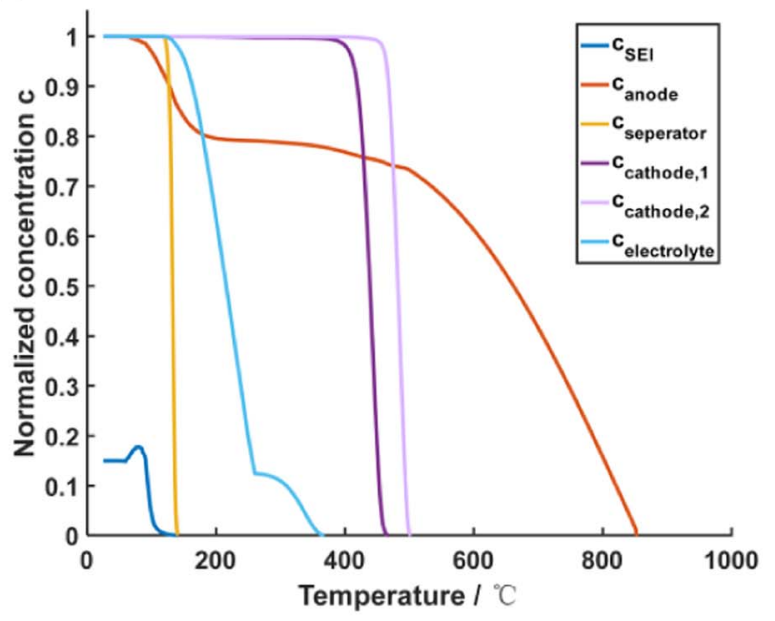

(d)

\section{Percentage of Total Heat Generation during Thermal Runaway}

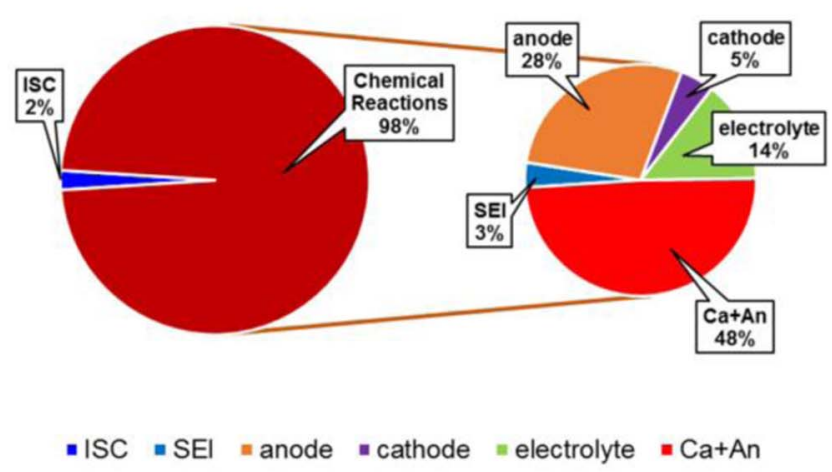

Figure 10. The status of reactions in the TR simulation. (a) the heat generation powers, (b) the normalized concentrations for reactants, (c) the integrated heat, (d) the percentage of total heat generation during TR.

Figure 12 shows the capacity degradation for the cell stored at $T_{\text {storage }}=120^{\circ} \mathrm{C}$. The cell can maintain a capacity larger than $80 \%$ within $4.6 \mathrm{~h}$, as the orange dots shown in Figure 12a. If the electrolyte leakage does not occur, which means that the $\Delta R_{\text {ele }}=0$ and $\kappa_{\text {LAM,ele }}$ $=0$ in the model, the capacity degradation will be delayed, and the capacity retention of $80 \%$ can last up to $10 \mathrm{~h}$. Figures $12 \mathrm{~b}-12 \mathrm{~g}$ compare the $\left\{y, x, Q_{\text {ca }}, Q_{\text {an }}, R_{\text {cell }}\right\}$ for the high temperature storage with or without electrolyte leakage. The changes in the stoichiometric coefficient $y$ and $x$ look similar for the two cases, as shown in Figures $12 \mathrm{~b}$ and $12 \mathrm{e}$. According to Eqs. 16 and 17, $c_{\mathrm{LAM}, \mathrm{ca}}$ and $c_{\mathrm{LAM}, \text { an }}$ are the normalized $Q_{\mathrm{ca}}$ and $Q_{\mathrm{an}}$. The capacity retention rate of $Q_{\mathrm{ca}}$ and $Q_{\mathrm{an}}$ can be reflected by $c_{\mathrm{LAM}, \mathrm{ca}}$ and $c_{\mathrm{LAM}, \text { an }}$, respectively. For the cell with electrolyte leakage, both $c_{\mathrm{LAM}, \mathrm{ca}}$ and $c_{\mathrm{LAM}, \text { an }}$ decrease much faster than that without electrolyte leakage, whereas the $R_{\text {cell }}$ increases faster than that without electrolyte leakage. Therefore, the major degradation mechanism for the high temperature storage with electrolyte leakage is the LAM and ORI. For the cell without electrolyte leakage, the value of $x$ in Eq. 3 drops from 0.86 to $0.72,83.7 \%$ of its original value, whereas the $c_{\mathrm{LAM}, \mathrm{ca}}$ drops to $81.6 \%$. Hence, the major degradation mechanism for high temperature storage without electrolyte leakage is a combination of LAM and LLI. Limited ORI also contributes to the capacity degradation without electrolyte leakage, but not as much as that with electrolyte leakage.
The duration for the capacity degradation to $80 \%$ for the cells stored at different $T_{\text {storage }}$ are compared in Figure 13. There is slight difference in the retention time to $80 \%$ capacity for the cell with and without electrolyte leakage, for $T_{\text {storage }} \leq 100^{\circ} \mathrm{C}$, because leakage only starts at temperature higher than $100^{\circ} \mathrm{C}$ for the cell used in experiments. For $T_{\text {storage }}>100^{\circ} \mathrm{C}$, the retention time to $80 \%$ capacity for cell with electrolyte decreases $100 \%$ faster than that without electrolyte leakage, indicating that avoiding electrolyte leakage can significantly improve the capacity retention time for the cell exposed to high temperatures. This modeling analysis helps understand the capacity loss mechanism at extremely high temperatures, and help extend the usage of the lithium-ion batteries at extreme working conditions.

The regeneration of SEI and its influence on the thermal runaway features.-Modeling analysis helps reveal the influence of the SEI regeneration on the TR features of lithium-ion batteries. $K_{\mathrm{SEI}}^{\mathrm{g}}$, as defined in Eq. 9, controls the speed of SEI regeneration. Figure 14a shows the influence of the $K_{\mathrm{SEI}}^{\mathrm{g}}$ on $\mathrm{d} T / \mathrm{d} t$ during TR. The $\mathrm{d} T / \mathrm{d} t$ can maintain at a specific level by the feedback gain $K_{\mathrm{SEI}}^{\mathrm{g}}$, indicating stable heat generation by the SEI decomposition and regeneration reaction. ${ }^{7} \mathrm{~d} T / \mathrm{d} t \approx$ $0.027^{\circ} \mathrm{C} \cdot \mathrm{min}^{-1}$ for the calibrated model with $K_{\mathrm{SEI}}^{\mathrm{g}}=6 . \mathrm{d} T / \mathrm{d} t$ rises from $0.022^{\circ} \mathrm{C} \cdot \mathrm{min}^{-1}$ to $0.034^{\circ} \mathrm{C} \cdot \mathrm{min}^{-1}$, when $K_{\mathrm{SEI}}^{\mathrm{g}}$ rises from 2 to 10 . The magnitude of stable heat generation caused by SEI decomposition and regeneration may vary for different kinds of carbon based 
(a)

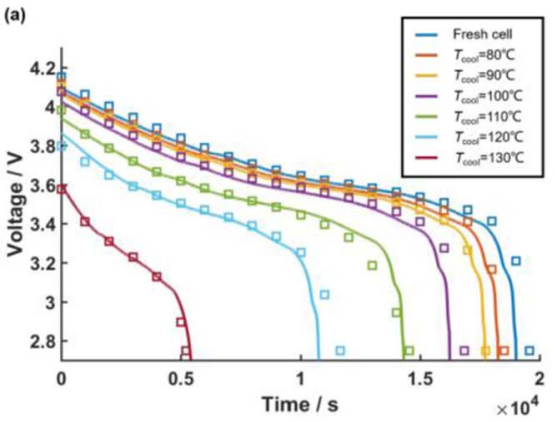

(b)

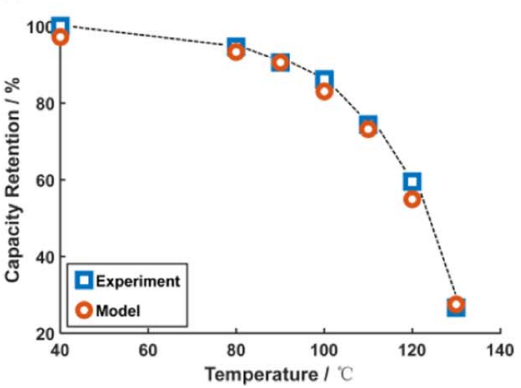

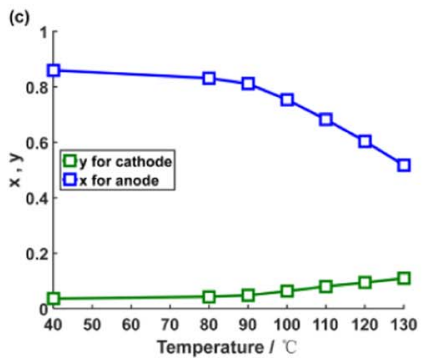
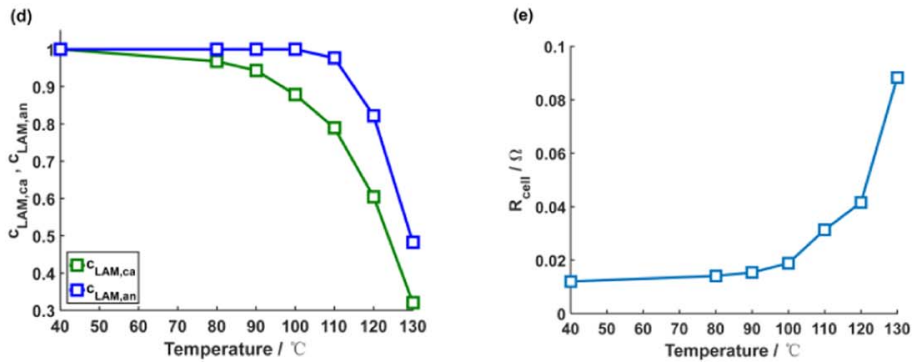

Figure 11. Experimental validation of the electrochemical-thermal coupled model in predicting the degradation at high temperature. (a) the discharge curve after cooling from high temperature, (b) the cell capacity after cooling from high temperature, (c) the $x$ and $y$ in the model, (d) the $Q_{\mathrm{ca}}$ and $Q_{\mathrm{an}}$ in the model, (e) the $R_{\mathrm{cell}}$ in the model.

(a) $120^{\circ} \mathrm{C}$ High T Storage

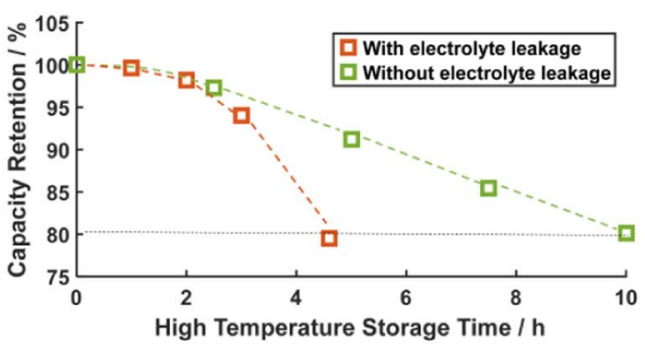

(b) $120^{\circ} \mathrm{C}$ High T Storage, with electrolyte leakage

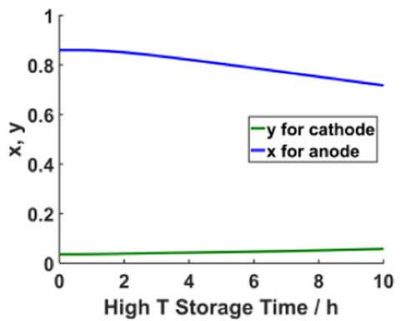

(e) $120^{\circ} \mathrm{C}$ High T Storage, without electrolyte leakage

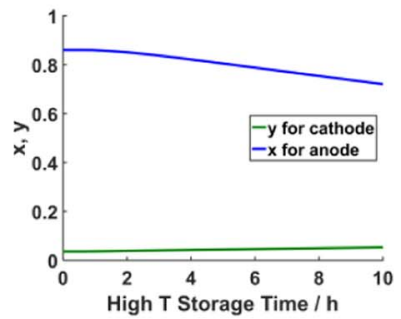

(c) $120^{\circ} \mathrm{C}$ High T Storage, with electrolyte leakage

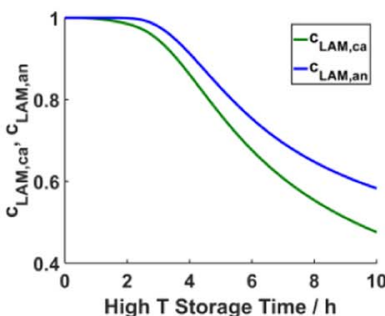

(f) $120^{\circ} \mathrm{C}$ High T Storage, without electrolyte leakage

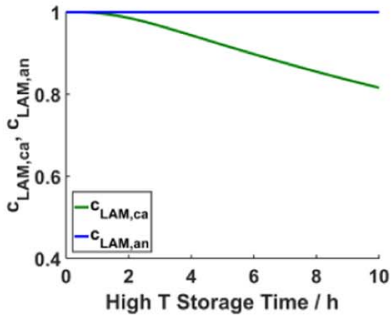

(d) $120^{\circ} \mathrm{C}$ High T Storage, with electrolyte leakage

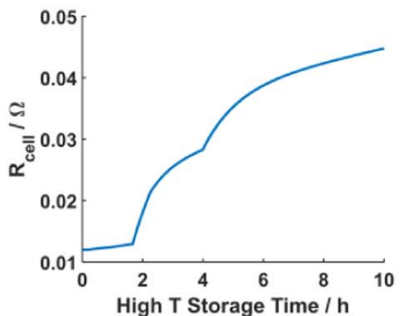

(g) $120^{\circ} \mathrm{C}$ High T Storage, without electrolyte leakage

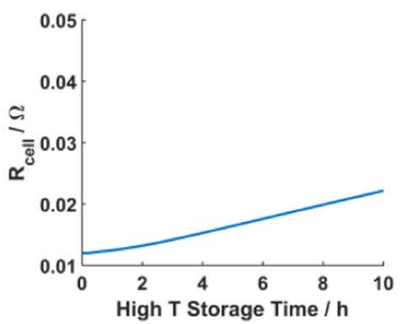

Figure 12. The capacity degradation under $T_{\text {storage }}=120^{\circ} \mathrm{C}$. (a) the capacity retention rate vs. storage time, (b) the $x$ and $y$ for high temperature storage with electrolyte leakage, (c) the $Q_{\mathrm{ca}}$ and $Q_{\mathrm{an}}$ for high temperature storage with electrolyte leakage, (d) the $R_{\text {cell }}$ high temperature storage with electrolyte leakage, (e) the $x$ and $y$ for high temperature storage without electrolyte leakage, (f) the $Q_{\mathrm{ca}}$ and $Q_{\mathrm{an}}$ for high temperature storage without electrolyte leakage, (d) the $R_{\text {cell }}$ high temperature storage without electrolyte leakage. 


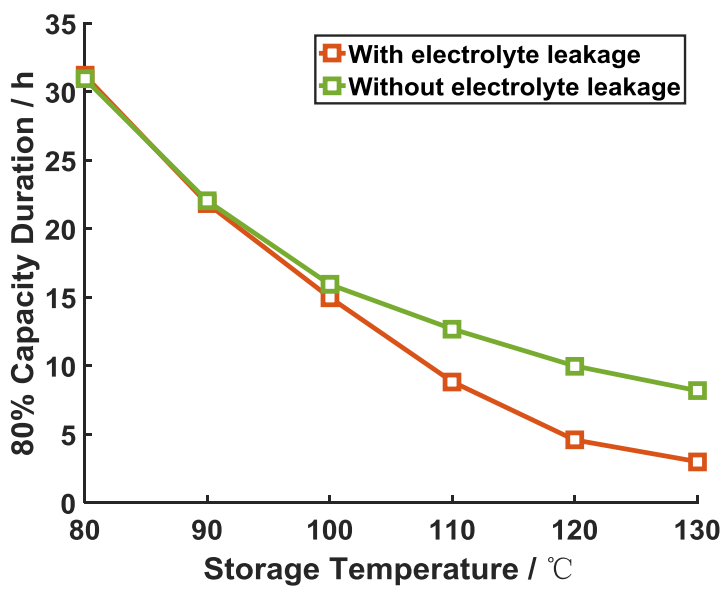

Figure 13. The endurance time for the cell degrades to $80 \%$ of its original capacity, for different storage temperatures, with and without electrolyte leakage.

anode materials, ${ }^{68}$ therefore $K_{\mathrm{SEI}}^{\mathrm{g}}$ is a critical parameter in the model, especially for the simulation between $60-120^{\circ} \mathrm{C}$. Figure $14 \mathrm{~b}$ shows that a larger increment of $c_{\text {SEI }}$ can be observed for the model with larger $K_{\mathrm{SEI}}^{\mathrm{g}}$, indicating a faster SEI regeneration in the reactions. However, $c_{\mathrm{SEI}}$ will always approach zero before the temperature reaches $150^{\circ} \mathrm{C}$,

(a)

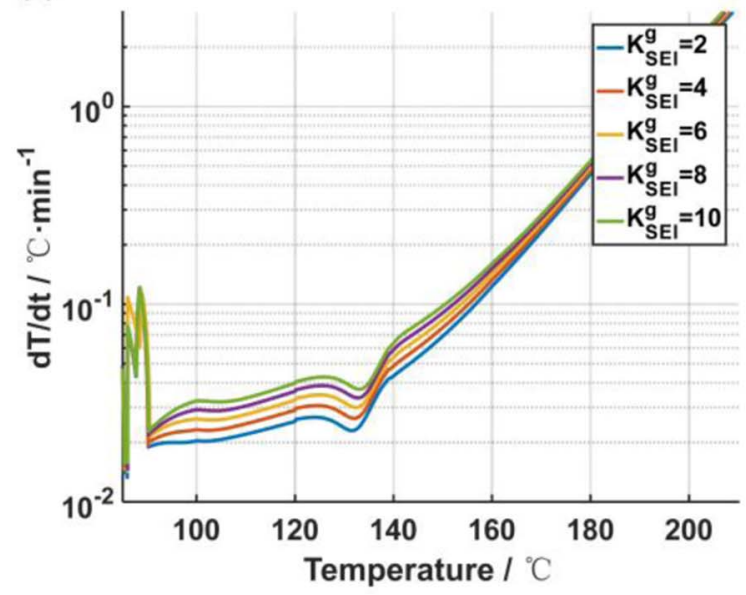

(c)

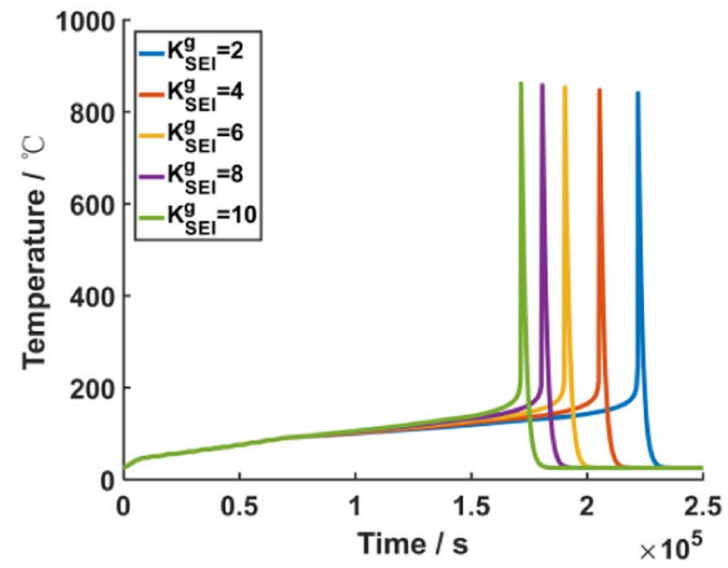

indicating that at $T>150^{\circ} \mathrm{C}$, the rate of SEI decomposition is much faster than that of the SEI regeneration. Figure $14 \mathrm{c}$ shows that the TR time will be shortened for larger values of $K_{\mathrm{SEI}}^{\mathrm{g}}$, because the value of $\mathrm{d} T / \mathrm{d} t$ increases. Figure $14 \mathrm{~d}$ displays the voltage profile during TR. Interestingly, the voltage for cell with smaller $K_{\mathrm{SEI}}^{\mathrm{g}}$ will be lower than that with larger $K_{\mathrm{SEI}}^{\mathrm{g}}$. This is because that the self-discharge lasts longer for a cell with smaller $K_{\mathrm{SEI}}^{\mathrm{g}}$.

Modeling analysis also helps reveal the influence of the SEI regeneration on the capacity degradation during TR. $K_{\mathrm{LLI}}$, as defined in Eq. 6, controls the rate of decrease of $x$, which is an important indicator of LLI. The value of $K_{\mathrm{LLI}}$ has little influence on the properties of heat generation, therefore we do not compare the $\mathrm{d} T / \mathrm{d} t$ curves here for different $K_{\mathrm{LLI}}$. Figure 15a illustrates the decreasing trend of $x$ for $K_{\mathrm{LLI}}$ from 2.3 to 3.1. A larger $K_{\mathrm{LLI}}$ will definitely accelerates the LLI at the anode. The downward slope at approximately $250^{\circ} \mathrm{C}$ indicates an ISC after the collapse of separator. Figure $15 \mathrm{~b}$ shows the difference in the voltage drop for the model with different $K_{\mathrm{LLI}}$. A larger $K_{\mathrm{LLI}}$ brings faster consumption of lithium inventory, leading to a faster voltage drop. Therefore $K_{\mathrm{LLI}}$ is a critical parameter for predicting the LLI in the model during thermal runaway.

The influence of the internal short circuit on the thermal runaway features.-The modeling analysis helps reveal the relationship between an ISC and TR. $T_{\text {ISC }}^{*}$, as defined by Figure $6 \mathrm{~b}$, determines the triggering temperature for ISC. Modeling analysis conducted for $T_{\text {ISC }}^{*}=\left\{135^{\circ} \mathrm{C}, 170^{\circ} \mathrm{C}, 210^{\circ} \mathrm{C}, 250^{\circ} \mathrm{C}\right\}$ show the influence of the ISC triggering time on the TR features. Figure 16a shows the triggering

(b)

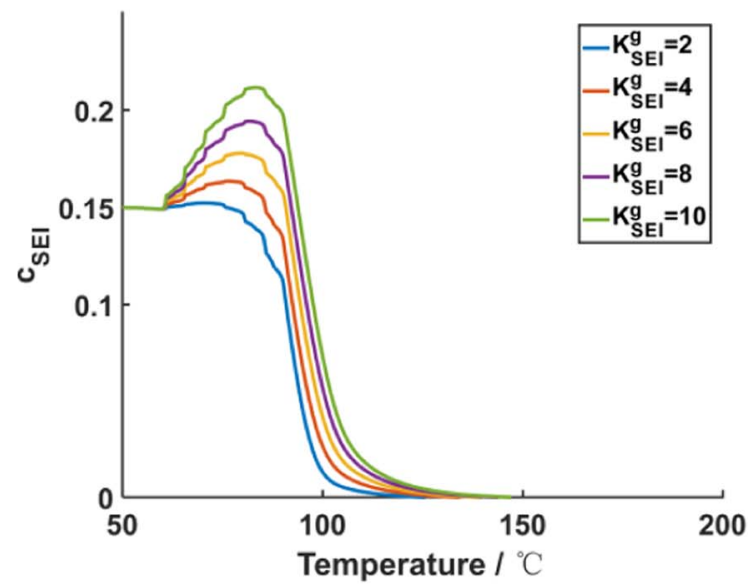

(d)

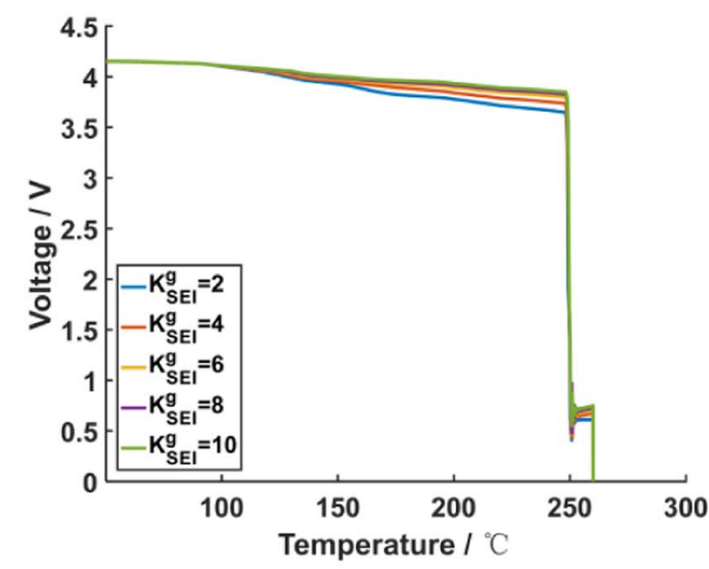

Figure 14. The influence of the SEI regeneration on the TR features. The influence of the $K_{\mathrm{SEI}}^{\mathrm{g}}$ on (a) the $\mathrm{d} T / \mathrm{d} t$ during TR, (b) the $c_{\mathrm{SEI}}$ during TR, (c) the $T-t$ during TR, (d) the $V$ - $t$ during TR. 
(a)

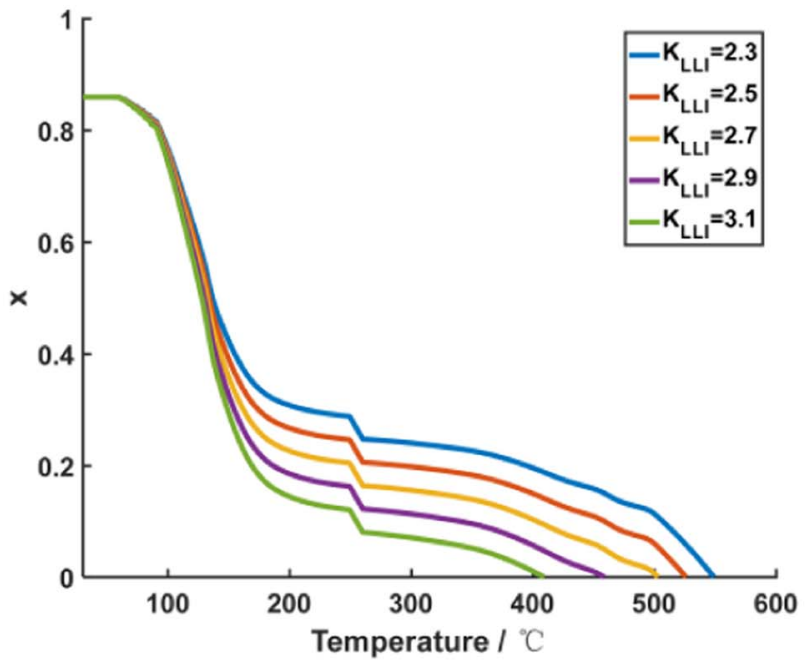

(b)

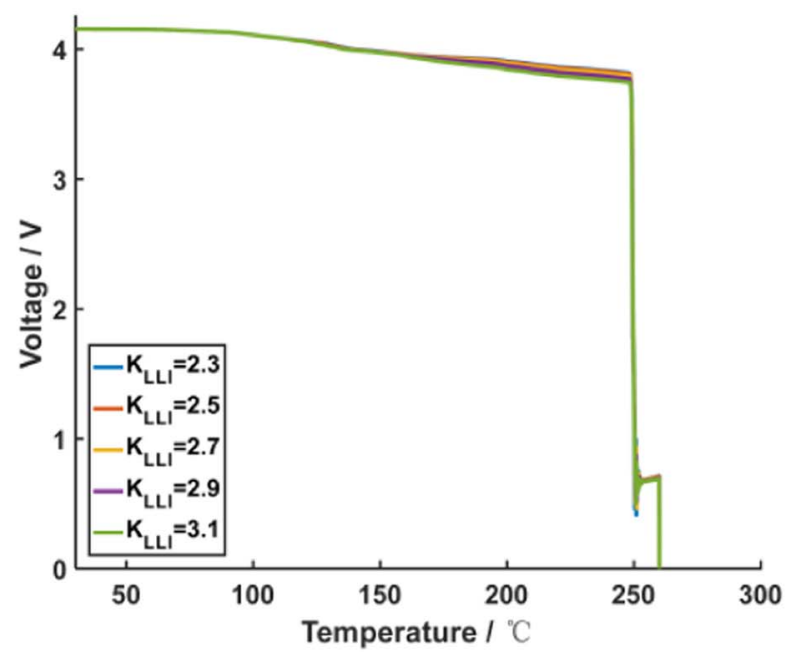

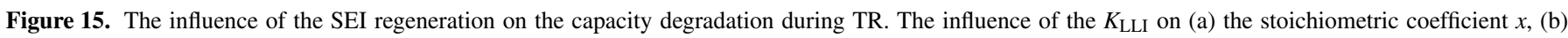
voltage profile.

time of TR can be significantly decreased for the case with $T_{\mathrm{ISC}}^{*}=$ $135^{\circ} \mathrm{C}$. While the trigger time of TR are quite close for other $T_{\text {ISC }}^{*}$, because the rate of temperature rise at high temperatures is already high. The $\mathrm{d} T / \mathrm{d} t$ curves in Figure 16b clearly show the influence of the ISC on the heat generation rate during TR (note that $\mathrm{d} T / \mathrm{d} t$ is proportional to the total heat generation power $Q$, as shown in Eq. 25. The speed up effect on the $\mathrm{d} T / \mathrm{d} t$ curves for $T_{\mathrm{ISC}}^{*}=135^{\circ} \mathrm{C}$ is obvious, compared to that for $T_{\text {ISC }}^{*}=210^{\circ} \mathrm{C} . \Delta H_{\text {ISC }}$, which is the total heat released during an ISC as defined in Eq. 35, has been marked in Figure 16b. $\Delta T_{\mathrm{ISC}}$ is in proportion with $\Delta H_{\mathrm{ISC}}$ as in Eq. 37 :

$$
\Delta T_{\mathrm{ISC}}=\frac{\Delta H_{\mathrm{ISC}}}{M \cdot C_{p}}
$$

Figure 16b displays that the lower $T_{\text {ISC }}^{*}$ is, the larger $\Delta H_{\text {ISC }}$ will be, and the higher temperature rise $\Delta T_{\text {ISC }}$ will be, therefore delaying the ISC to higher temperature is useful to mitigating battery TR. Our observations in the modeling analysis not only match the experimental results in our recent paper, ${ }^{78}$ but also helps interpret the mechanisms of failure for some data sets with different $T_{\text {ISC }}^{*}$.

Figures $16 \mathrm{c}-16 \mathrm{f}$ provides some ARC data that can validate the proposed coupled electrochemical-thermal model. Figures $16 \mathrm{c}$ and $16 \mathrm{~d}$ are the ARC test results for the 25Ah lithium-ion cell with same materials, but manufactured in a different batch. The ceramic coating on the separator of the cell is not uniform, therefore an ISC will occur at $135^{\circ} \mathrm{C}$, when the shrinkage starts for the PE base. All the $T-t$, $V$ - $t, \mathrm{~d} T / \mathrm{d} t$ curves look similar with the simulation case with $T_{\mathrm{ISC}}^{*}=$ $135^{\circ} \mathrm{C}$, as in Figures 16a and $16 \mathrm{~b}$. The rapid heat release during TR does not occur until the temperature rises to $250^{\circ} \mathrm{C}$ or higher. Figures $16 \mathrm{e}$ and $16 \mathrm{f}$ provide another case for a $3.3 \mathrm{Ah}$ pouch cell with similar cell chemistries. The ISC occurs around $205^{\circ} \mathrm{C}$, giving rise to a small peak in the $\mathrm{d} T / \mathrm{d} t$ curve (circled in Figure 16f), similar to that shown in Figure 16b. Figures 16c-16f further convince us that the coupled electrochemical-thermal model has high fidelity in capturing the underlying mechanisms during TR.

The $\Delta H_{\mathrm{ISC}}=22260 \mathrm{~J}$ for $T_{\mathrm{ISC}}^{*}=135^{\circ} \mathrm{C}$ only occupies approximately $7 \%$ of the total electric energy that is charged into the cell. Since the efficacy coefficient for electric energy release is set as $\zeta=$ $28 \%$ in Eq. 23, these results imply that the electric energy has not been fully released during ISC. The low rate of energy release during ISC may be attributed to the capacity degradation caused by electrolyte leakage. Hence, simulations were conducted to compare the ISC behavior for a cell with and without electrolyte leakage. The results are shown in Figure 17. Although the ISC occurs at similar times, TR oc- curs immediately after ISC is triggered for the cell without electrolyte leakage, as shown in Figure 17a. The maximum temperature during TR rises from $869.1^{\circ} \mathrm{C}$ to $907.5^{\circ} \mathrm{C}$ (nearly $40^{\circ} \mathrm{C}$ increase), for the cell without electrolyte leakage. Figure $17 \mathrm{~b}$ shows that the ISC can last longer for the cell without electrolyte leakage, therefore the $\Delta H_{\text {ISC }}$ increases to $53443 \mathrm{~J}$ ( $16 \%$ of the charged electrical energy). The ISC does not end until the rapid oxidation-reduction occurs, therefore there is still some electric energy left in the cell. The ISC process is forced to be shut down in the model, because the rapid oxidation-reduction will break the circuit that can forms stable ISC current. In summary, the cell becomes more dangerous if there is no electrolyte leakage before an ISC occurs. From this perspective, releasing the electrolyte in time before the occurrence of an ISC will help reduce the hazard during TR. However, the exhaust flammable electrolyte may be ignited outside the cell, arousing other safety problems, and will be discussed in our future work. ${ }^{79}$

The influence of the degree of ISC $\left(R_{\mathrm{ISC}}^{*}\right)$ on the TR behavior has been discussed by modeling analysis. The temperature curves $(T-t$ and $\mathrm{d} T / \mathrm{d} t)$ look similar for $R_{\mathrm{ISC}}^{*}=0.01 \Omega$ and $R_{\mathrm{ISC}}^{*}=0.001 \Omega$, as shown in Figure 18, indicating the heat generation rate for different $R_{\mathrm{ISC}}^{*}$ can be similar. Figure $18 \mathrm{~b}$ reveals the mechanism underlying this phenomenon: because a smaller $R_{\mathrm{ISC}}^{*}$ leads to lower level of voltage after an ISC is triggered. A lower level of voltage denotes a lower level

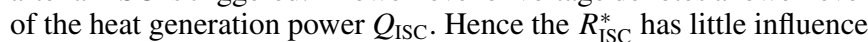
on the TR behavior, as long as it is sufficiently small to reflect a hard ISC.

Moreover, we try to study the influence of the efficacy coefficient $\zeta$ on the TR behavior using the model. Figure 19a shows that if the value of $\zeta$ increases to $100 \%$, the TR will be much severe, and the TR will be triggered much more rapid once $T$ reaches $T_{\text {ISC }}^{*}=135^{\circ} \mathrm{C}$. The maximum temperature during TR will further increase from $907.5^{\circ} \mathrm{C}$ to $937.5^{\circ} \mathrm{C}$, due to the increase in $\zeta$. Figure $19 \mathrm{~b}$ further confirms that a more severe hazard might be brought by the increase in $\zeta$. In conclusion, the parameter $\zeta$ has a big influence on the TR behavior of lithium-ion cells. The accurate measurement of $\zeta$ still requires further study. Ref. 17 suggests that $\zeta$ should include the effects of venting, which is also interesting for further investigation.

Finally, the results of modeling analysis have been concluded by Figure 20. The lower value of the $T_{\text {ISC }}^{*}$ is, the larger influence will be on the TR features, because the capacity degradation will significantly reduce the cell capacity at higher temperatures. The leakage of electrolyte can cause up to $40^{\circ} \mathrm{C}$ difference in the maximum temperature at TR for the cell used in this study, whereas the $\zeta$ can cause $30^{\circ} \mathrm{C}$ 
(a) Simulation

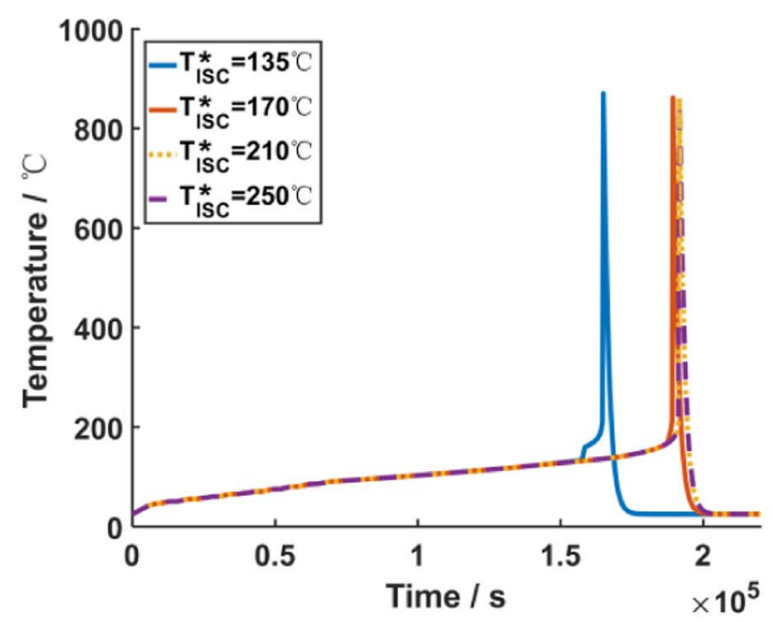

(c) Phenomenon in other experiments No.1, $T_{\text {ISC }}^{\star}=135^{\circ} \mathrm{C}$

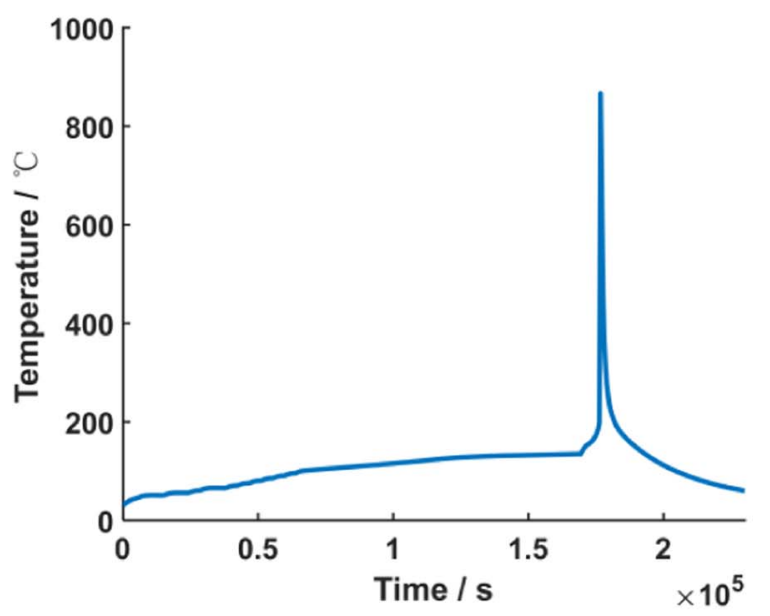

(e) Phenomenon in other experiments No.2, $T_{1 \mathrm{SC}}^{\star}=205^{\circ} \mathrm{C}$

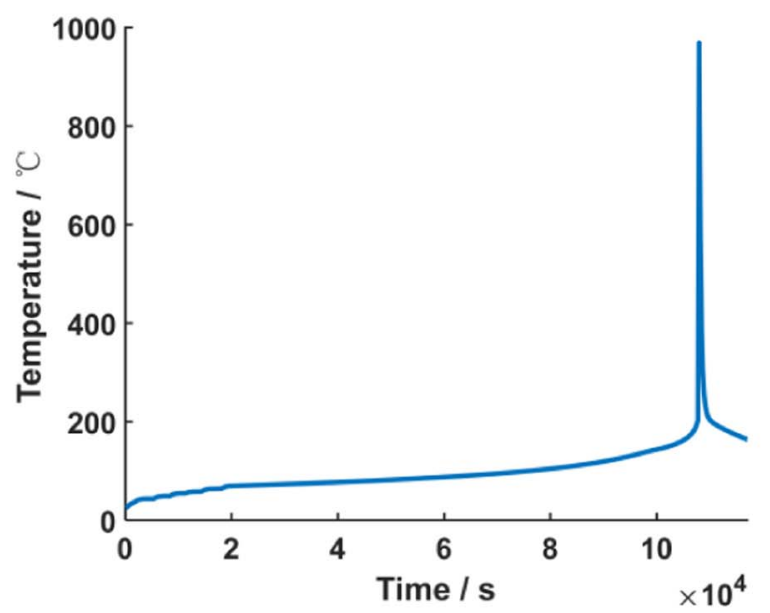

(b) Simulation

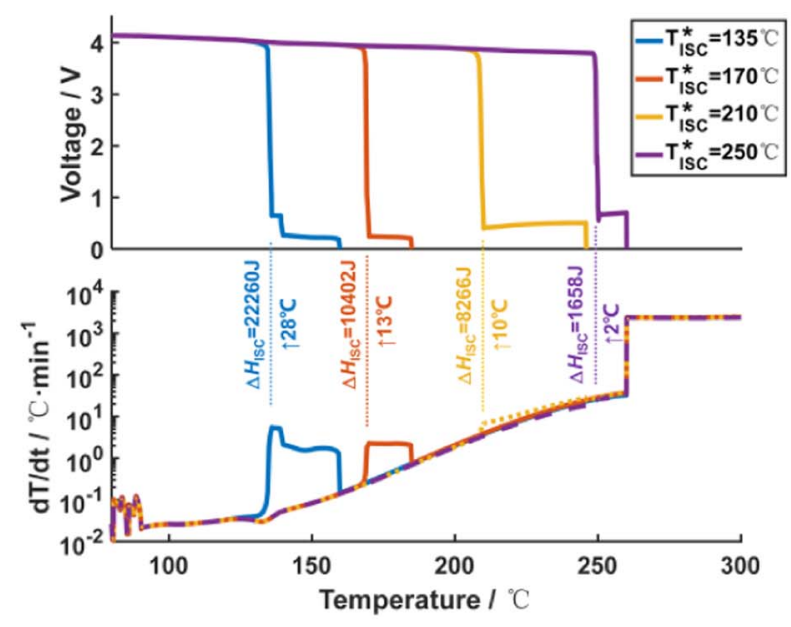

(d) Phenomenon in other experiments No.1, $T_{\mathrm{ISC}}^{\star}=135^{\circ} \mathrm{C}$
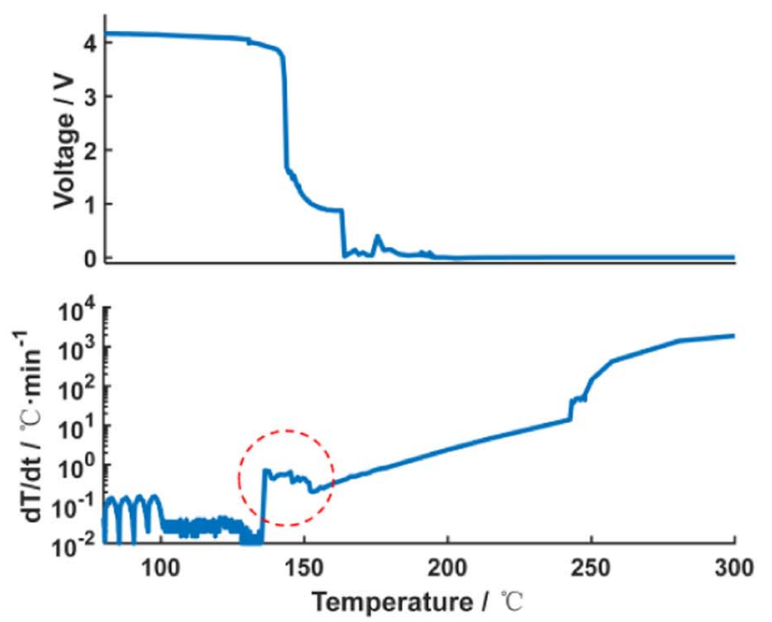

(f) Phenomenon in other experiments No.2, $T_{\mathrm{ISC}}^{\star}=205^{\circ} \mathrm{C}$
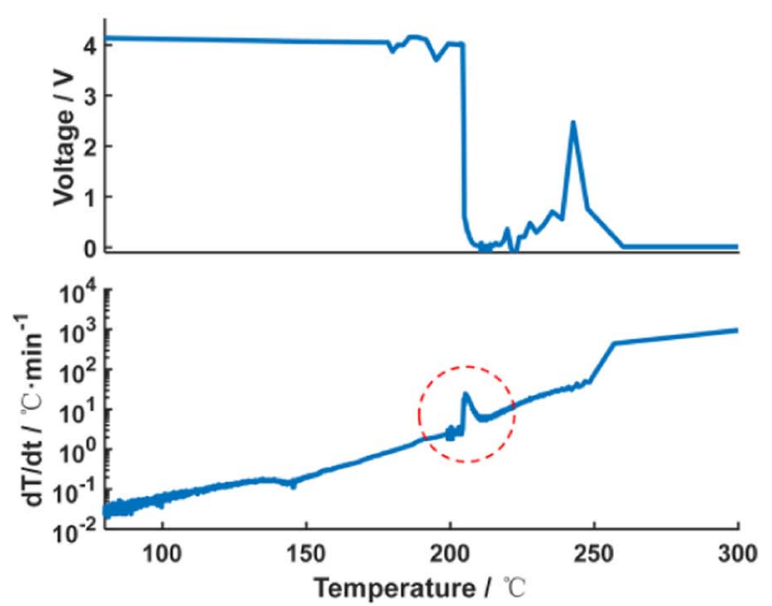

Figure 16. The influence of the ISC temperature ( $T_{\text {ISC }}^{*}$ ) on the TR behaviors. (a) $T$ - $t$ results for modeals with different $T_{\text {ISC }}^{*}$, (b) $\mathrm{d} T / \mathrm{d} t$ results for models with different $T_{\text {ISC }}^{*}$, (c) A real case with $T_{\text {ISC }}^{*}=135^{\circ} \mathrm{C}$, the $T$ - $t$ curve, (d) A real case with $T_{\text {ISC }}^{*}=135^{\circ} \mathrm{C}$, the $V$ - $t$ and d $T / \mathrm{d} t$ curve, (e) A real case with $T_{\text {ISC }}^{*}=205^{\circ} \mathrm{C}$, the $T$ - $t$ curve, (f) A real case with $T_{\mathrm{ISC}}^{*}=205^{\circ} \mathrm{C}$, the $V$ - $t$ and $\mathrm{d} T / \mathrm{d} t$ curve. 
(a)

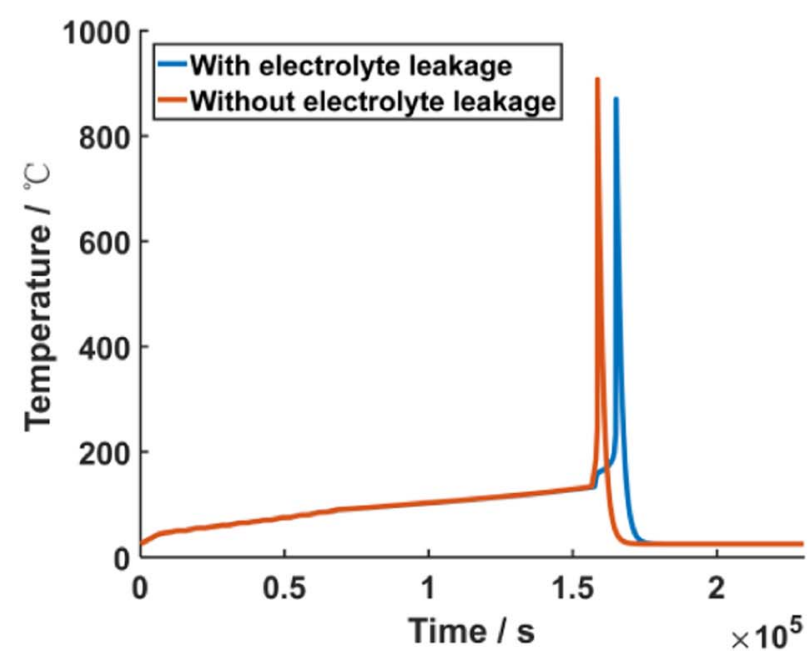

(b)

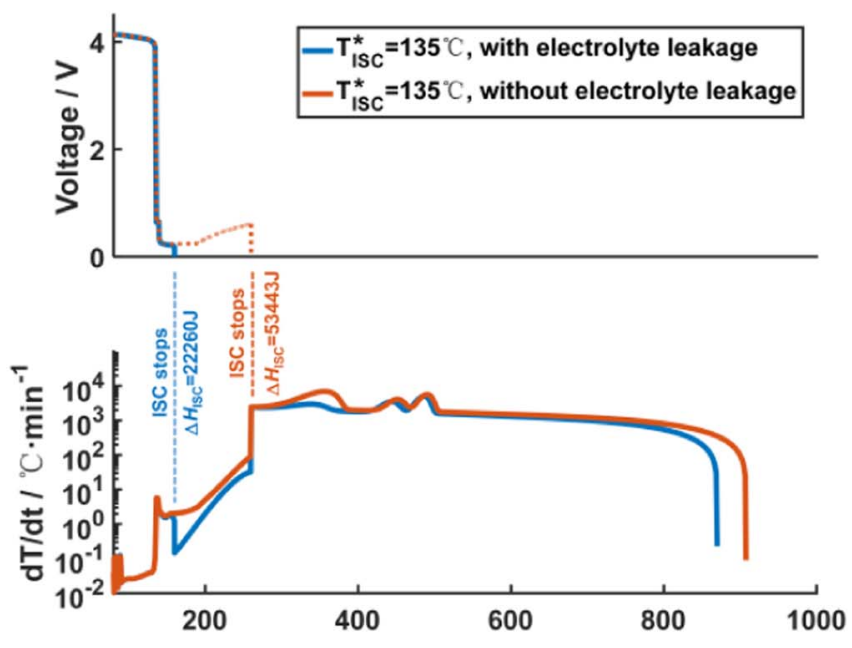

Figure 17. The influence of the electrolyte leakage on the ISC behavior during TR. (a) The $T-t$ curve, (b) The $V-t$ and $\mathrm{d} T / \mathrm{d} t$ curve .

(a)

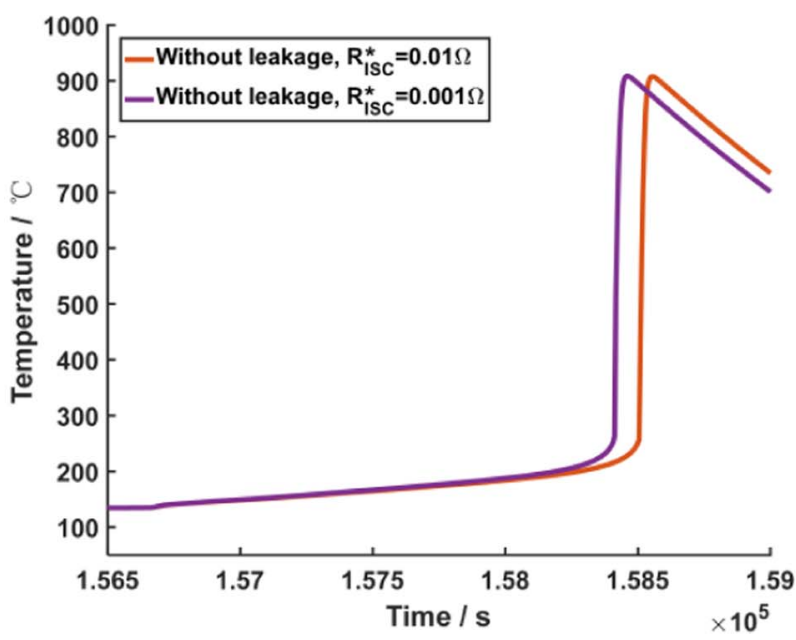

(b)
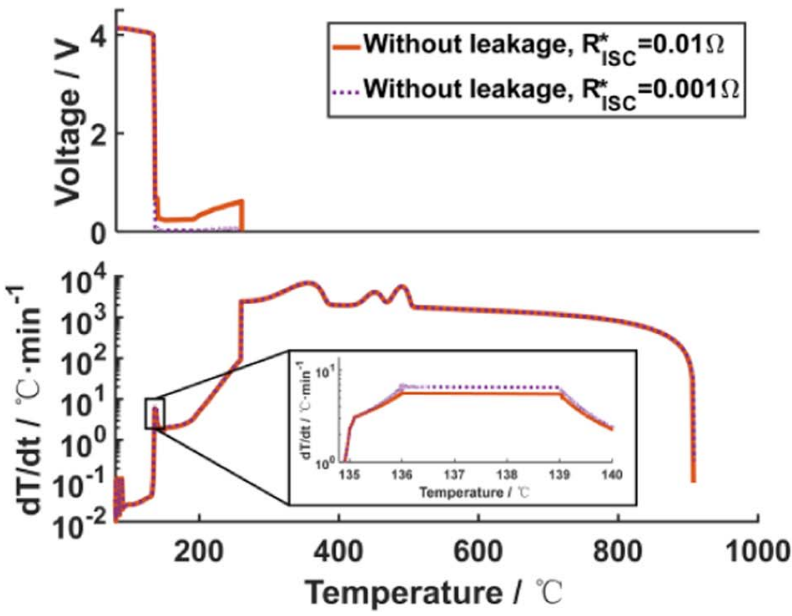

Figure 18. The influence of the $R_{\mathrm{ISC}}^{*}$ on the TR behavior. (a) The $T$ - $t$ curve, (b) The $V$ - $t$ and $\mathrm{d} T / \mathrm{d} t$ curve.

(a)

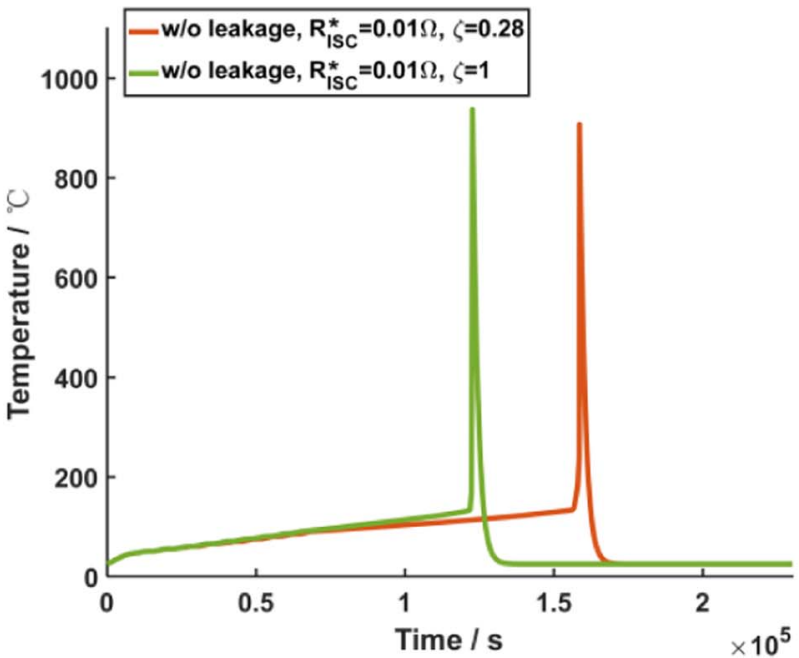

(b)
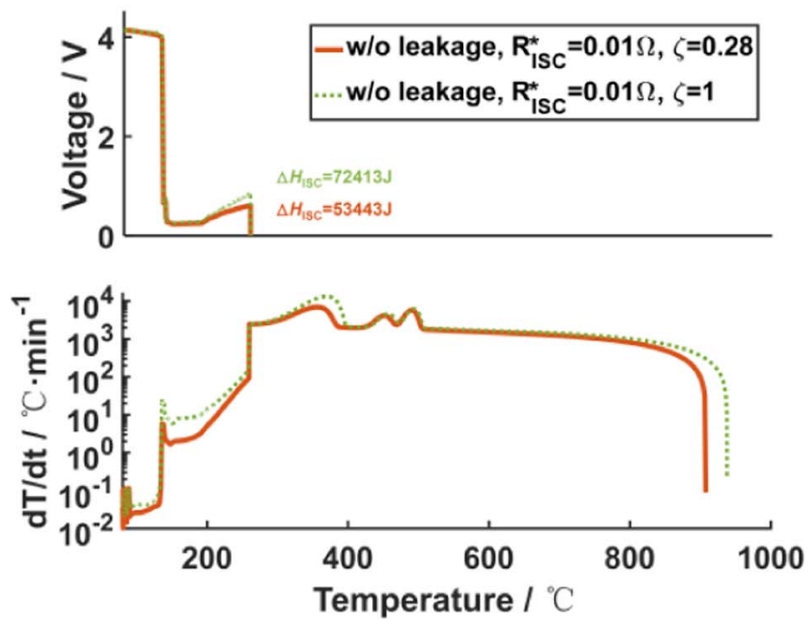

Figure 19. The influence of the efficacy coefficient $\zeta$ on the TR behavior. (a) The $T-t$ curve, (b) The $V-t$ and $\mathrm{d} T / \mathrm{d} t$ curve. 


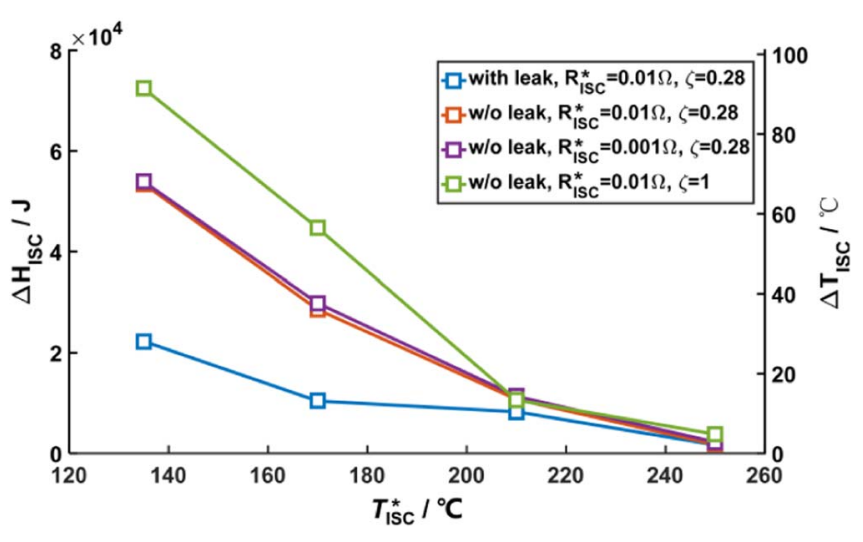

Figure 20. The influence of correlated parameters in the ISC model on the TR features.

difference. Figure 20 tells us that if the degree of ISC can be controlled by the electrolyte concentration and the heat release efficiency of joule heating, we can reduce the maximum temperature of the cell by up to $100^{\circ} \mathrm{C}$. According to Figures 17-19, the occurrence of an ISC is a critical factor to trigger TR, therefore managing the triggering temperature of ISC will help postpone the TR to higher level. However, the total heat generation by ISC is not the major heat source that heat the cell to $800^{\circ} \mathrm{C}$ or higher. Figure 21 summarizes the percentage of the heat generation by ISC in the total heat generation of TR, for $R_{\mathrm{ISC}}^{*}=0.01 \Omega, \varsigma=0.28$, no matter there is electrolyte leakage or not. The percentage of the heat generation by ISC rises when $T_{\text {ISC }}^{*}$ decreases, indicating the triggering condition might be severer if massive ISC occurs at lower temperature. Less than $10 \%$ of the total heat is released by ISC, confirmed by our modeling analysis. The thermal energy released by chemical reactions covers the majority of the total energy released during TR. The rapid oxidation-reduction reaction is the main reaction that determines the maximum temperature, and the mechanism requires further study.

Effect of critical temperatures on the thermal runaway features.Further modeling analysis are conducted to discuss the critical temperatures that may significantly influence the TR features in this section. The collapse of the separator sets a key tipping point for the energy release style during TR, as shown in Figure 7. Before the collapse of separator, the reactions occur within their own systems. However, after the collapse of separator, the cathode (oxidizer) and anode (re-

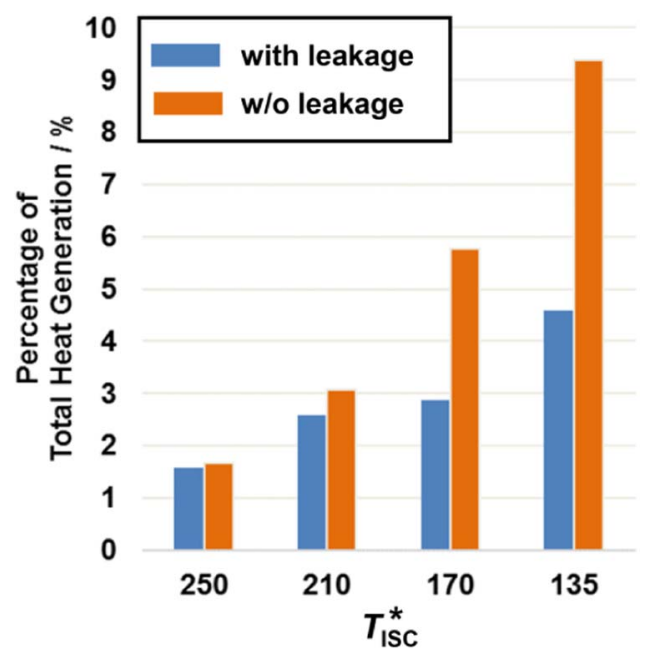

Figure 21. The percentage of the heat generation by ISC in the total heat generation of TR, $R_{\mathrm{ISC}}^{*}=0.01 \Omega, \varsigma=0.28$. ducer) have chances to electrically contact each other, and rapid reactions will start at high temperatures. The critical temperatures that represent the critical point during TR include: 1) $T_{\text {sep,mlt }}$, the melting point of the base of the separator, $T_{\text {sep,mlt }}=120 \sim 140^{\circ} \mathrm{C}$ for PE, and $T_{\text {sep,mlt }}=160 \sim 180^{\circ} \mathrm{C}$ for PP; 2) $T_{\text {sep,clp }}$, the collapse temperature of the separator, $T_{\text {sep,clp }}=T_{\text {sep,mlt }}$ for a single-layer separator, while for a multilayer separator $T_{\text {sep,clp }}$ can be up to $200^{\circ} \mathrm{C}$ or higher; 3) $T_{\text {ISC }}^{*}$, the temperature for ISC, to the best knowledge of the authors, most of the test results points that $T_{\mathrm{ISC}}^{*}=T_{\text {sep,clp. }}$. However, under the cases when the cell is under mechanical abuse, $T_{\text {ISC }}^{*}$ can be lower than $T_{\text {sep,clp }}$; 4) $T_{\text {onset,Ca+An }}$, the onset temperature of the rapid oxidation-reduction reaction between the cathode and anode, as shown in Figure 7 and Figures 22d and 22e.

The critical behavior of TR can be interpreted if the relationship between the four critical temperatures is clear. Generally, the relationship among $T_{\text {sep,mlt }}, T_{\text {sep,clp }}$ and $T_{\text {ISC }}^{*}$ is clear, as shown in Figures $22 \mathrm{a}-22 \mathrm{c}$. However, the relationship between $T_{\text {onset,Ca+An }}$ and $T_{\text {ISC }}^{*}$ is still questionable. In Ref. 73 the authors believe that $T_{\text {onset,Ca+An }}$ can be lower than $T_{\text {ISC }}^{*}$, because the oxygen and other oxidizers that are released by the cathode can migrate from the cathode to the anode, trigging TR before ISC, as shown in Figure 22d, here we called Case 1 for the style of TR. On the contrary, in this paper, we have $T_{\text {onset,Ca+An }}>T_{\text {ISC }}^{*}$, which is called as Case 2 , as shown in Figure 22e. Case 2 has two branches, one is that the heat released by ISC can further trigger TR, which is called the Case 2.1, whereas another one is that the heat released by ISC cannot further trigger TR, which is called the Case 2.2. We emphasize Case 2.2, because if the conditions that lead to Case 2.2 are well understood, then chances that the TR is triggered by ISC will be minimized.

Modeling analysis are conducted for the Case 1, Case 2.1 and Case 2.2, respectively. In Case 1 , the $T_{\text {onset,Ca+An }}=130^{\circ} \mathrm{C}$, referring to the onset temperature for oxygen release as in Ref. 80, and $T_{\mathrm{ISC}}^{*}=$ $170^{\circ} \mathrm{C}>T_{\text {onset, }, \mathrm{Ca}+\mathrm{An}}$. In Case $2.1, T_{\mathrm{ISC}}^{*}=170^{\circ} \mathrm{C}<T_{\text {onset, } \mathrm{Ca}+\mathrm{An}}=260^{\circ} \mathrm{C}$, whereas in Case $2.2, T_{\mathrm{ISC}}^{*}=170^{\circ} \mathrm{C}<T_{\text {onset, } \mathrm{Ca}+\mathrm{An}}=600^{\circ} \mathrm{C}$. Figure 23 displays the simulation results for the three cases. Figure 23a shows that the TR is triggered immediately when the temperature reaches $T_{\text {onset,Ca+An }}=130^{\circ} \mathrm{C}$ for Case 1 , there will be no ISC because the circuit for short has been broken in advance. Interestingly, there is less TR for Case 2.2, although a fast temperature rise is still triggered at $T_{\mathrm{ISC}}^{*}=$ $170^{\circ} \mathrm{C}$, similar to Case 2.1. The maximum temperature for Case 2.2 is $472.6^{\circ} \mathrm{C}$, which is much lower than that for Case $2.1\left(861.6^{\circ} \mathrm{C}\right)$, because the thermal energy of the rapid oxidation-reduction reaction has not been released. Eq. 38 defines the condition that when the fierce oxidation-reduction reaction will not be initiated:

$$
T_{\mathrm{ISC}}^{*}+\Delta T_{\mathrm{ISC}}+\sum_{z} \Delta T_{z}<T_{\text {onset, } \mathrm{Ca}+\mathrm{An}}
$$

where $\Delta T_{\text {ISC }}$ is defined in Eq. 37, and $\sum \Delta T_{z}$ is the total temperature rise caused by chemical reactions of cell materials, satisfying:

$$
\sum_{z} \Delta T_{z}=\frac{\Delta H_{\mathrm{chem}}}{M \cdot C_{p}}
$$

where $\Delta H_{\text {chem }}$ is defined in Eq. 34. Figure 23b shows that if the criterion in Eq. 38 holds, the maximum temperature during TR will be much lower, because the rapid oxidation-reduction reaction will not occur. If we can form a thermal barrier as defined in Eq. 38, the TR hazard can be significantly reduced.

The major contributions of the proposed model and future work.-.- Here we conclude the major contributions of the proposed electrochemical-thermal coupled failure model for predicting the thermal runaway behavior of lithium-ion batteries.

1. The model coupling is two-way, including the "electrochemical $\rightarrow$ thermal" (by Eqs. 22, 23) and "thermal $\rightarrow$ electrochemical" (Eqs. 6-13, 16-21), rather than one-way coupling of "thermal $\rightarrow$ electrochemical" in most of previous literature, to the best knowledge of the authors. The two-way 
(a) Normal condition

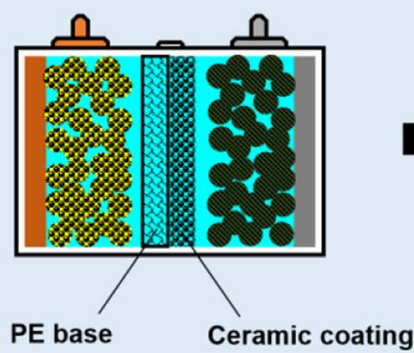

(b) Separator base melting

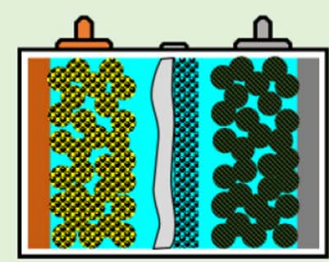

$T_{\text {sep,mlt }}$ (c) Separator collapse \& ISC
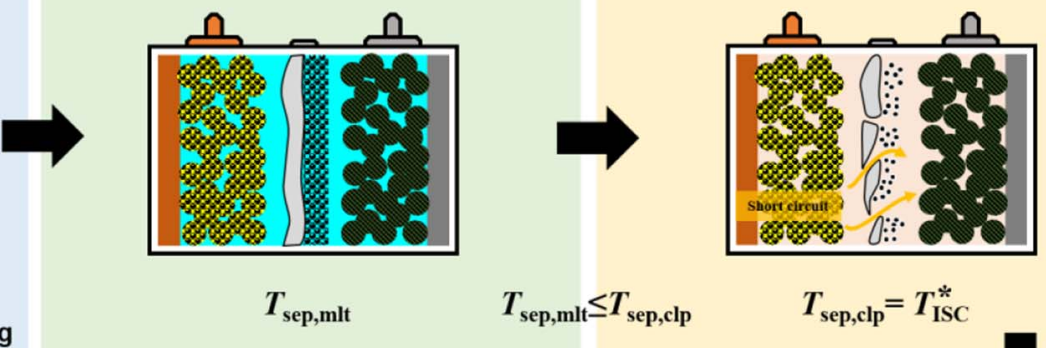

$T_{\text {sep,clp }}=T_{\text {ISC }}^{*}$

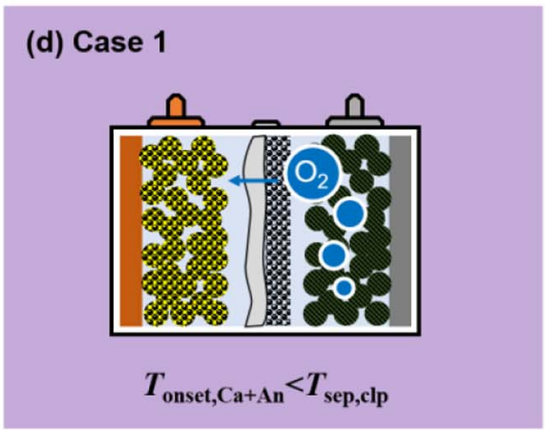

(e) Case 2
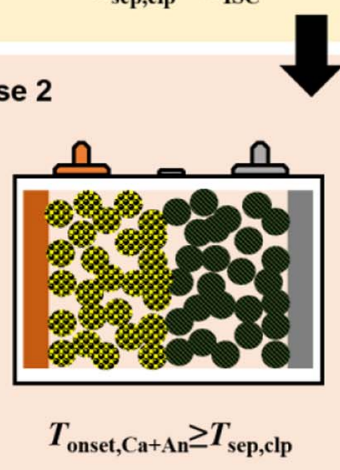

Figure 22. Schematic illustrating the influence of the critical temperatures $\left(T_{\text {sep,mlt }}, T_{\text {sep,clp }}, T_{\text {ISC }}^{*}, T_{\text {onset,Ca+An }}\right)$ on the TR behaviors. (a) Normal condition, (b) The moment when the base of the separator collapses, (c) The moment when ISC occurs, (d) The Case 1, for which the $T_{\text {onset,Ca+An }}<T_{\text {sep,c-lp }}$, (e) The Case 2 , for which $T_{\text {onset,Ca+An }} \geq T_{\text {sep,clp }}$.

coupling makes the modeling analysis on the heat generation by ISC more reliable, and proving that two-way coupling based on physical equations is possible in TR simulations.

2. New physical based functions are established, e.g. Eqs. 6, 9, 10, 14 , although some of the parameters are still empirical. Those physical based equations can guide further research on quantify specific side reactions with parameters involved in two-way coupling.

3. Successfully quantify the proportion of the ISC in the total heat generation during TR, with proper experimental validation. The quantified results indicate that the ISC is not the major heat source during TR. Maybe one day we would observe that there will be battery TR without ISC, as predicted by the modeling analysis.

(a)

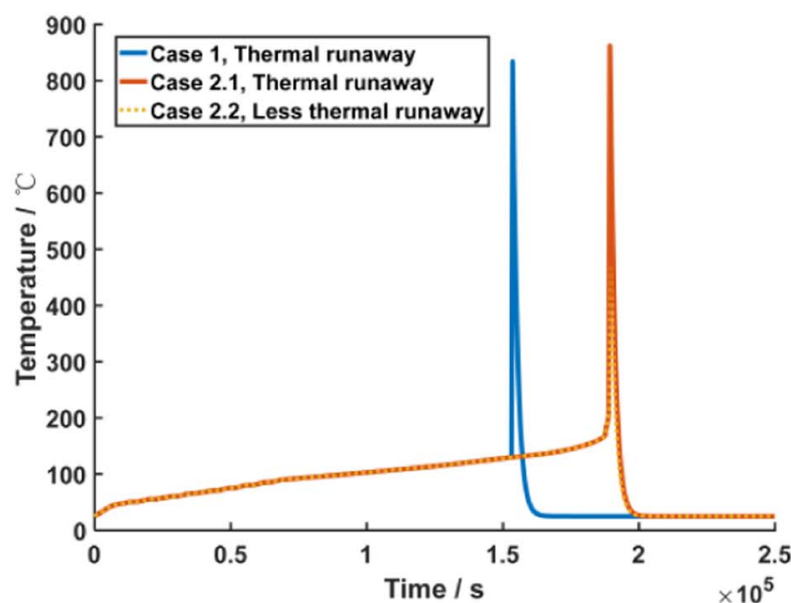

We also give our suggestions on the future work, to further improve the capability of the electrochemical-thermal coupled battery failure model. We encourage further research to focus on the "electrochemical-thermal" way of coupling, which can solidify the two-way coupling of the model, making it closer to reflect the real physical/chemical processes during TR. And next significant progress may be fulfilled in the simulation considering the influence of battery state-of-charge on the TR behavior:

1. More functions that can describe the coupling way of "electrochemical $\rightarrow$ thermal" should be built, in order to simulate the influence of battery state-of-charge on the TR behaviors. Based on some unsystematic results, we believe that the proposed

(b)

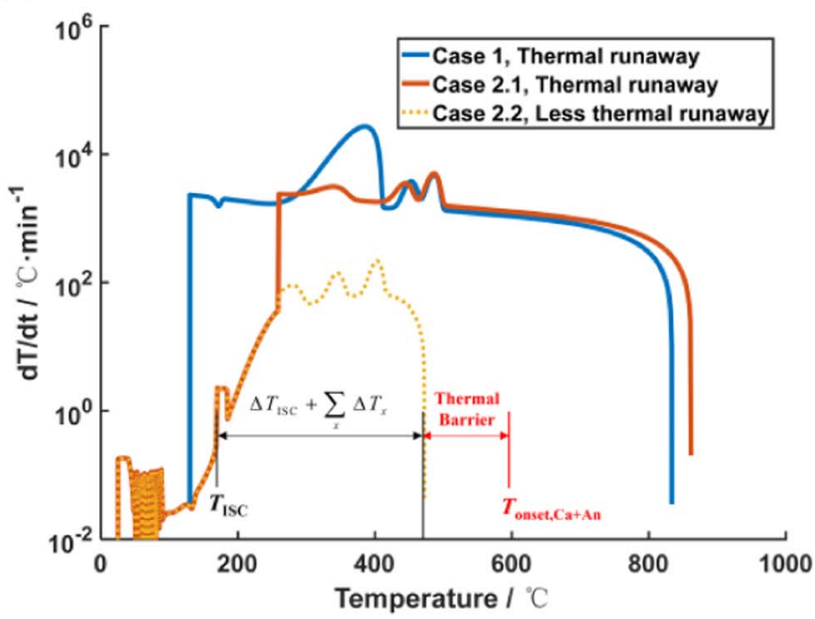

Figure 23. The judgement condition of TR, if the critical temperatures are known for the lithium-ion cell. (a) $T$ - $t$ curve for different cases, (b) $\mathrm{d} T$-d $t$ curve for different cases. 
model may be easily extended for cells with state-of-charge larger than $75 \%$. However, more data are required to come to a more solid conclusion.

2. The influence of state-of-charge on the TR behavior should be established by setting new equations between $c_{\text {LAM }}$ in the electrochemical model and $c_{\mathrm{ca}}$, can in the thermal model. More data are needed to quantify the electrochemical-thermal coupled relationship.

\section{Summary}

A coupled electrochemical-thermal TR model for lithium-ion batteries has been built to simultaneously predict the voltage and temperature during TR. The model can fit the experimental data well; it captures well the underlying dynamics of (1) the capacity degradation at high temperatures; (2) the ISC caused by the thermal failure of separator; and (3) the chemical reactions of the cell components that release heat under extreme temperature. The modeling analysis that discusses capacity degradation under extreme temperatures can be used to extend the usage of lithium-ion batteries at extreme high temperature. Our modeling analysis also studied the influence of the SEI decomposition and regeneration on the TR behavior. The discussion on the critical parameters relating with the ISC process benefits the safety design of lithium-ion battery with lower hazard levels during TR.

\section{Acknowledgments}

This work is supported by the National Key R\&D Program of China under the grant No. 2018YFB0104404, the National Natural Science Foundation of China under the grant No. 51706117 and U1564205, the Ministry of Science and Technology of China under the grant No. 2016YFE0102200, and the China Postdoctoral Science Foundation under the grant No. 2017M610086. The first author thanks the support of "Young Elite Scientist Sponsorship Program" from China Association for Science and Technology.

\begin{tabular}{|c|c|c|}
\hline \multicolumn{3}{|c|}{ List of Symbols } \\
\hline \multicolumn{3}{|c|}{ Parameters } \\
\hline$A_{\mathrm{S}}$ & $\mathrm{m}^{2}$ & Area for heat dissipation \\
\hline$A_{z}$ & $\mathrm{~s}^{-1}$ & $\begin{array}{l}\text { Frequency factor of the Arrhenius Equation, } \\
\text { for specific reaction } z\end{array}$ \\
\hline$b_{\xi}$ & 1 & Offset for $\xi, b_{\xi}=0.83$ \\
\hline$c_{z}$ & 1 & $\begin{array}{l}\text { Normalized concentration for specific } \\
\text { reaction } z\end{array}$ \\
\hline$C_{p}$ & $\mathrm{~J} \cdot \mathrm{kg}^{-1} \cdot \mathrm{K}^{-1}$ & Specific heat capacity \\
\hline$E_{a, z}$ & $\mathrm{~J} \cdot \mathrm{mol}^{-1}$ & $\begin{array}{l}\text { Activation energy of the Arrhenius Equation } \\
\text { for specific reaction } z\end{array}$ \\
\hline$g_{z}$ & 1 & Correction term of the Arrhenius Equation \\
\hline$h_{\text {conv }}$ & $\mathrm{W} \cdot \mathrm{m}^{-2} \cdot \mathrm{K}^{-1}$ & Convective coefficient for heat dissipation \\
\hline$I$ & A & Current \\
\hline$K$ & 1 & Gain constant of a specific physical process \\
\hline$M$ & $\mathrm{~kg}$ & Mass of the battery cell \\
\hline$m_{z}$ & $\mathrm{~g}$ & Mass of specific active material $z$ \\
\hline$n_{\mathrm{z}, 1}, n_{\mathrm{z}, 2}$ & 1 & Order of the Arrhenius Equations \\
\hline$Q$ & $\mathrm{~W}$ & Heat generation power \\
\hline$Q_{z}$ & $\mathrm{~W}$ & Heat generation power, for specific reation \\
\hline$Q_{\mathrm{ca}}, Q_{\mathrm{an}}$ & $\mathrm{Ah}$ & Capacity of the cathode and anode \\
\hline$R$ & $\Omega$ & Resistance \\
\hline$R^{0}$ & $\mathrm{~J} \cdot \mathrm{mol}^{-1} \cdot \mathrm{K}^{-1}$ & Ideal gas constant \\
\hline$R_{\text {cell }}$ & $\Omega$ & Internal resistance of the battery cell \\
\hline$R_{\mathrm{ISC}}^{*}$ & $\Omega$ & $\begin{array}{l}\text { Critical resistance for the fierce internal } \\
\text { short circuit }\end{array}$ \\
\hline SOC & 1 & State-of-charge \\
\hline SYS & I & Independent thermodynamic system \\
\hline$t, \tau$ & $\mathrm{s}$ & Time \\
\hline$T$ & ${ }^{\circ} \mathrm{C}, \mathrm{K}$ & Temperature \\
\hline
\end{tabular}

\begin{tabular}{|c|c|}
\hline$T_{\text {cool }}$ & ${ }^{\circ} \mathrm{C}$ \\
\hline$T_{\text {ISC }}^{*}$ & ${ }^{\circ} \mathrm{C}$ \\
\hline$T_{\text {onset }, z}$ & ${ }^{\circ} \mathrm{C}, \mathrm{K}$ \\
\hline$T_{\text {Ref }}$ & ${ }^{\circ} \mathrm{C}$ \\
\hline$T_{\text {sep,clp }}$ & ${ }^{\circ} \mathrm{C}$ \\
\hline$T_{\text {sep,mlt }}$ & ${ }^{\circ} \mathrm{C}$ \\
\hline$T_{\text {storage }}$ & ${ }^{\circ} \mathrm{C}$ \\
\hline$T_{\xi}$ & $\mathrm{K}$ \\
\hline$U_{\mathrm{ca}}, U_{\mathrm{an}}$ & $\mathrm{V}$ \\
\hline V & $\mathrm{V}$ \\
\hline$V_{\mathrm{mdl}}$ & V \\
\hline$x, y$ & 1 \\
\hline$x_{0,0}$ & 1 \\
\hline$\frac{\mathrm{d} T}{\mathrm{~d} t}$ & ${ }^{\circ} \mathrm{C}^{-1}, \mathrm{~K}$ \\
\hline$\frac{\mathrm{d} U}{\mathrm{~d} T}$ & $\mathrm{~V} \cdot \mathrm{K}^{-1}$ \\
\hline Greek & \\
\hline$\Delta h_{z}$ & $\mathrm{~J} \cdot \mathrm{g}^{-1}$ \\
\hline$\Delta H$ & $\mathrm{~J}$ \\
\hline$\Delta R$ & $\Omega$ \\
\hline$\Delta T$ & ${ }^{\circ} \mathrm{C}, \mathrm{K}$ \\
\hline$\Delta t$ & $\mathrm{~s}$ \\
\hline$\Delta x$ & 1 \\
\hline$\zeta$ & 1 \\
\hline$\eta$ & 1 \\
\hline$\kappa$ & $\mathrm{s}^{-1}$ \\
\hline$\kappa_{z}$ & $\mathrm{~s}^{-1}$ \\
\hline$\xi$ & 1 \\
\hline
\end{tabular}

Cooling temperature for ARC test with early termination

Critical temperature for the fierce internal short circuit

Onset temperature for specific reaction $z$ Reference temperature for calculating the cell voltage, $T_{\text {Ref }}=25^{\circ} \mathrm{C}$

Collapse temperature of the separator Melting temperature of the separator Temperature for high temperature exposure/storage

Reference temperature for $\xi, T_{\xi}=523 \mathrm{~K}$ Open circuit potential of the cathode and anode

Voltage

Voltage of the model

Stoichiometric coefficients of the anode and cathode

Initial value of $x_{0}$

$\mathrm{C}^{-1}, \mathrm{~K}^{-1}$ Temperature rate

Entropic potential change

Enthalpy for specific reaction $z$, normalized by mass

Enthalpy, total heat generation for specific process

Changes in $R$ ( $R$ is for resistance)

Changes in $T$ ( $T$ is for temperature)

Time constant regulating the speed of oxidation-reduction reaction

Changes in $x$

Efficacy factor to regulate the non-ohmic heat generation by internal short circuit Columbic coefficient

Change rate of a specific parameter Change rate of a specific reaction $z$ Factor to represent the temperature effect on the resistance

\begin{tabular}{ll}
\multicolumn{1}{c}{ Subscripts } & Initial value \\
0 & Anode \\
an & Cathode \\
ca & Oxidation-reduction reaction between \\
Ca+An & Cathode and anode \\
chem & Heat dissipation \\
dis & Electrolyte \\
ele & Internal short circuit \\
ISC & Loss of active material \\
LAM & Loss of lithium inventory \\
LLI & Resistance \\
$R$ & Separator \\
sep & For total heat generation \\
Total & For specific chemical reactions, $z$ can be SEI, \\
$z$ & anode, separator, cathode, 1, cathode,, 2, \\
& electrolyte, et al. as listed in Table II. \\
Superscripts & Decomposition \\
d & Dissolution \\
diss & Regeneration \\
G & Reference \\
ref &
\end{tabular}

\section{ORCID}

Xuning Feng (1) https://orcid.org/0000-0002-5790-5164

Dongsheng Ren (1D https://orcid.org/0000-0002-8764-9819

\section{References}

1. G. E. Blomgren, J. Electrochem. Soc., 164, A5019 (2017). 
2. N. E. Galushkin, N. N. Yazvinskaya, and D. N. Galushkin, J. Electrochem. Soc., 165 A1303 (2018).

3. S. Yayathi, W. Walker, D. Doughty, and H. Ardebili, J. Power Sources, 329, 197 (2016).

4. Y. S. Duh, K. H. Lin, and C. S. Kao, J. Therm. Analysis, 132, 1677 (2018).

5. B. Liu, J. Zhang, C. Zhang, and J. Xu, Eng. Fail. Anal., 91, 315 (2018).

6. F. Schipper, E. M. Erickson, C. Erk, J. Y. Shin, F. F. Chesneau, and D. Aurbach, Review-Recent advances and remaining challenges for lithium ion battery cathodes. J. Electrochem. Soc., 164, A6220 (2017).

7. X. Feng, M. Ouyang, X. Liu, L. Lu, Y. Xia, and X. He, Energy Storage Materials, 10, $246(2018)$

8. T. Wu, H. Chen, Q. Wang, and J. Sun, J. Hazard. Mater, 344, 733 (2018).

9. P. Huang, Q. Wang, K. Li, P. Ping, and J. Sun, Sci. Rep., 5, 7788 (2015).

10. P. Huang, P. Ping, K. Li, H. Chen, Q. Wang, J. Wen, and J. Sun, Appl. Energ., 183 659 (2016)

11. Q. Wang, P. Ping, X. Zhao, G. Chu, J. Sun, and C. Chen, J. Power Sources, 208, 210 (2012)

12. A. Lecocq, G. G. Eshetu, S. Grugeon, N. Martin, S. Laruelle, and G. Marlair, J. Power Sources, 316, 197 (2016)

13. L. Lu, X. Han, J. Li, J. Hua, and M. Ouyang, J. Power Sources, 226, 272 (2013).

14. M. Ouyang, M. Zhang, X. Feng, L. Lu, J. Li, X. He, and Y. Zheng, J. Power Sources, 294, 272 (2015).

15. Y. Zheng, M. Ouyang, X. Han, L. Lu, and J. Li, J. Power Sources, 377, 161 (2018).

16. X. Feng, Y. Pan, X. He, L. Wang, and M. Ouyang, Journal of Energy Storage, 18, 26 (2018).

17. P. T. Coman, E. C. Darcy, C. T. Veje, and R. E. White, J. Electrochem. Soc., 164 A587 (2017).

18. P. Keil, S. F. Schuster, J. Wilhelm, J. Travi, A. Hauser, R. C. Karl, and A. Jossen, J. Electrochem. Soc., 163, A587 (2016).

19. D. P. Finegan, E. Darcy, M. Keyser, B. Tjaden, T. M. M. Heenan, R. Jervis, J. J. Bailey, R. Malik, N. T. Vo, O. V. Magdysyuk, R. Atwood, M. Drakopoulos, M. Dimichiel, A. Rack, G. Hinds, D. J. L. Brett, and P. R. Shearing, Energy Environ. Sci., 10, 1377 (2017).

20. B. Liu, S. Yin, and J. Xu, Appl. Energ., 183, 278 (2016).

21. R. Spotnitz and J. Franklin, J. Power Sources, 113, 81 (2003).

22. P. Ping, Q. Wang, P. Huang, J. Sun, and C. Chen, Appl. Energ., 129, 261 (2014).

23. F. Larsson, J. Anderson, P. Andersson, and B. Mellander, J. Electrochem. Soc., 163, A2854 (2016).

24. C. F. Lopez, J. A. Jeevarajan, and P. P. Mukherjee, J. Electrochem. Soc., 162, A1905 (2015)

25. X. Feng, J. Sun, M. Ouyang, F. Wang, X. He, L. Lu, and H. Peng, J. Power Sources, 275, 261 (2015).

26. D. P. Finegan, M. Scheel, J. B. Robinson, B. Tjaden, I. Hunt, T. J. Mason, J. Millichamp, M. D. Michiel, G. J. Offer, G. Hinds, D. J. L. Brett, and P. R. Shearing, Nat. Commun., 6, 6924 (2015).

27. I. Bloom, B. W. Cole, J. J. Sohn, S. A. Jones, E. G. Polzin, V. S. Battaglia, G. L. Henriksen, C. Motloch, R. Richardson, T. Unkelhaeuser, D. Ingersoll, and H. L. Case, J. Power Sources, 101, 238 (2001)

28. J. Wang, P. Liu, J. Hicks-Garner, E. Sherman, S. Soukiazian, M. Verbrugge, H. Tataria, J. Musser, and P. Finamore, J. Power Sources, 196, 3942 (2011).

29. M. Dubarry, C. Truchot, and B. Y. Liaw, J. Power Sources, 219, 204 (2012).

30. X. Han, M. Ouyang, L. Lu, J. Li, Y. Zheng, and Z. Li, J. Power Sources, 251, 38 (2014)

31. J. Christensen and J. Newman, J. Electrochem. Soc., 105, A1416 (2003)

32. J. Christensen and J. Newman, J. Electrochem. Soc., 152, A818 (2005)

33. R. Spotnitz, J. Power Sources, 113, 72 (2003).

34. P. Ramadass, B. Haran, P. M. Gomadam, R. E. White, and B. N. Popov, J. Electrochem. Soc., 151, A196 (2004).

35. R. Deshpande, M. Verbrugge, Y. T. Cheng, J. Wang, and P. Liu, J. Electrochem. Soc., 159, A1730 (2012)

36. M. Ouyang, X. Feng, X. Han, L. Lu, Z. Li, and X. He, Appl. Energ., 165, 48 (2016).

37. M. N. Richard and J. R. Dahn, J. Electrochem. Soc., 146, 2068 (1999).

38. N. Tanaka and W. G. Bessler, Solid State Ionics, 262, 70 (2014).
39. M. Zhang, L. Liu, A. Stefanopoulou, J. Siegel, L. Lu, X. He, and M. Ouyang, J. Electrochem. Soc., 164, A2738 (2017)

40. M. Zhang, J. Du, L. Liu, A. Stefanopoulou, J. Siegel, L. Lu, X. He, X. Xie, and M. Ouyang, J. Electrochem. Soc., 164, A3038 (2017).

41. D. P. Finegan, B. Tjaden, T. M. M. Heenan, R. Jervis, M. D. Michiel, A. Rack, G. Hinds, D. J. L. Brett, and P. R. Shearing, J. Electrochem. Soc., 164, A3285 (2017).

42. P. T. Coman, E. C. Darcy, C. T. Veje, and R. E. White, Appl. Energ., 203, 189 (2017).

43. E. Sahraei, M. Kahn, J. Meier, and T. Wierzbicki, RSC Adv, 5, 80369 (2015).

44. J. Lamb and C. J. Orendorff, J. Power Sources, 247, 189 (2014).

45. S. Liu, N. Imanishi, T. Zhang, A. Hirano, Y. Takeda, O. Yamamoto, and J. Yang, $J$ Electrochem. Soc., 157, A1092 (2010).

46. N. S. Schauser, K. J. Harry, D. Y. Parkinson, H. Watanabe, and N. P. Balsara, J. Electrochem. Soc., 162, A398 (2015).

47. D. Ren, K. Smith, D. Guo, X. Han, X. Feng, L. Lu, M. Ouyang, and J. Li, J. Electrochem. Soc., 165, A2167 (2018).

48. I. Uchida, H. Ishikawa, M. Mohamedi, and M. Umeda, J. Power Sources, 119-121, 821 (2003).

49. T. G. Zavalis, M. Behm, and G. Lindbergh, J. Electrochem. Soc., 159, A848 (2012).

50. S. Santhanagopalan, P. Ramadass, and Z. Zhang, J. Power Sources, 194, 550 (2009).

51. W. Fang, P. Ramadass, and Z. Zhang, J. Power Sources, 248, 1090 (2014).

52. W. Zhao, G. Luo, and C. Y. Wang, J. Electrochem. Soc., 162, A1352 (2015).

53. X. Feng, C. Weng, M. Ouyang, and J. Sun, Appl. Energ., 161, 168 (2016).

54. X. Feng, X. He, L. Lu, and M. Ouyang, J. Electrochem. Soc., 165, A155 (2018).

55. M. N. Richard and J. R. Dahn, J. Electrochem. Soc., 146, 2078 (1999).

56. T. D. Hatchard, D. D. MacNeil, A. Basu, and J. R. Dahn, J. Electrochem. Soc., 148, A755 (2001).

57. D. D. MacNeil and J. R. Dahn, J. Phys. Chem. A, 105, 4430 (2001)

58. D. Ren, X. Liu, X. Feng, L. Lu, M. Ouyang, J. Li, and X. He, Appl. Energ., 228, 633 (2018).

59. G. H. Kim, A. Pesaran, and R. Spotnitz, J. Power Sources, 170, 476 (2007).

60. X. Feng, X. He, M. Ouyang, L. Lu, P. Wu, C. Kulp, and S. Prasser, Appl. Energ., 154, 74 (2015).

61. X. Feng, L. Lu, M. Ouyang, J. Li, and X. He, Energy, 115, 194 (2016).

62. P. T. Coman, S. Rayman, and R. E. White, J. Power Sources, 307, 56 (2016).

63. P. T. Coman, S. Mátéfi-Tempfli, C. T. Veje, and R. E. White, J. Electrochem. Soc., 164, A1858 (2017).

64. C. H. Lee, S. J. Bae, and M. Jang, J. Power Sources, 293, 498 (2015).

65. M. Doyle, T. F. Fuller, and J. Newman, J. Electrochem. Soc., 140, 1526 (1993).

66. P. Ping, Q. Wang, Y. Chung, and J. Wen, Appl. Energ., 205, 1327 (2017).

67. X. Feng, J. Sun, M. Ouyang, X. He, L. Lu, X. Han, M. Fang, and H. Peng, J. Power Sources, 272, 457 (2014)

68. Z. Chen, Y. Qin, Y. Ren, W. Lu, C. Orendorff, E. P. Roth, and K. Amine, Energy Environ. Sci., 4, 4023 (2011).

69. F. Larsson, S. Bertilsson, M. Furlani, I. Albinsson, and B. E. Mellander, J. Power Sources, 373, 220 (2018)

70. Y. Dai, L. Cai, and R. E. White, J. Electrochem. Soc., 160, A182 (2013).

71. J. Zhang, B. Wu, Z. Li, and J. Huang, J. Power Sources, 259, 106 (2014).

72. H. Kim, M. Kong, K. Kim, I. Kim, and H. Gu, J. Power Sources, 171, 917 (2007).

73. H. Wang, A. Tang, and K. Huang, Chinese J. Chem., 29(8), 1583 (2011).

74. D. H. Doughty and A. A. Pesaran, Vehicle battery safety roadmap guidance. Oct. 2012.

75. X. Liu, D. Ren, H. Hsu, X. Feng, G. Xu, M. Zhuang, H. Gao, L. Lu, X. Han, Z. Chu, J. Li, X. He, K. Amine, and M. Ouyang, Joule, 2(10), 2047 (2018).

76. X. Feng, M. Fang, X. He, M. Ouyang, L. Lu, H. Wang, and M. Zhang, J. Power Sources, 255, 294 (2014)

77. B. Liu, H. Zhao, H. Yu, J. Li, and J. Xu, Electrochim. Acta, 256, 172 (2017).

78. S. Zheng, L. Wang, X. Feng, and X. He, J. Power Sources, 378, 527 (2018).

79. X. Feng, S. Zheng, X. He, L. Wang, Y. Wang, D. Ren, and M. Ouyang, Frontiers in Energy Research, accepted abstract (2018).

80. S. M. Bak, E. Hu, Y. Zhou, X. Yu, S. D. Senanayake, S. J. Cho, K. B. Kim K. Y. Chung, X. Q. Yang, and K. W. Nam, ACS Appl. Mater. Inter, 6, 22594 (2014). 